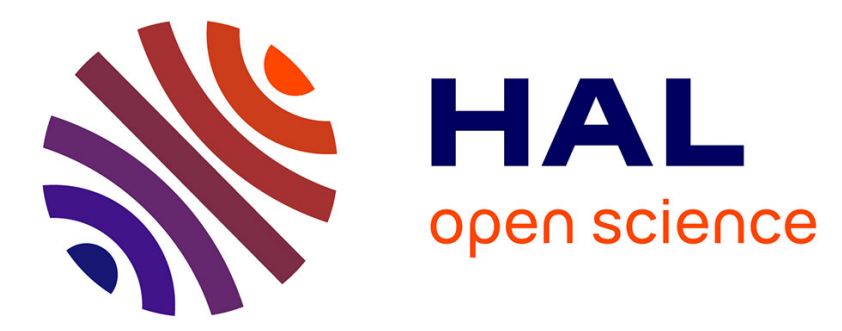

\title{
Hydrologically Aided Interpolation of Daily Precipitation and Temperature Fields in a Mesoscale Alpine Catchment
}

Nicolas Le Moine, Frédéric Hendrickx, Joël Gailhard, Rémy Garçon, Frédéric Gottardi

\section{To cite this version:}

Nicolas Le Moine, Frédéric Hendrickx, Joël Gailhard, Rémy Garçon, Frédéric Gottardi. Hydrologically Aided Interpolation of Daily Precipitation and Temperature Fields in a Mesoscale Alpine Catchment. Journal of Hydrometeorology, 2015, 16 (6), pp.2595-2618. 10.1175/JHM-D-14-0162.1 . hal-01237960

\section{HAL Id: hal-01237960 \\ https://hal.sorbonne-universite.fr/hal-01237960}

Submitted on 4 Dec 2015

HAL is a multi-disciplinary open access archive for the deposit and dissemination of scientific research documents, whether they are published or not. The documents may come from teaching and research institutions in France or abroad, or from public or private research centers.
L'archive ouverte pluridisciplinaire HAL, est destinée au dépôt et à la diffusion de documents scientifiques de niveau recherche, publiés ou non, émanant des établissements d'enseignement et de recherche français ou étrangers, des laboratoires publics ou privés. 


\title{
Hydrologically Aided Interpolation of Daily Precipitation and Temperature Fields in a Mesoscale Alpine Catchment
}

\author{
NiCOLAS LE MOINE \\ Sorbonne Universités, UPMC Université Paris 06, CNRS, EPHE, UMR Metis, Paris, France \\ FRÉDÉRIC HENDRICKX \\ Électricité de France R\&D, Chatou, France \\ JoËL GAILHARD, RÉMY GARÇON, AND FRÉDÉRIC GOTTARDI \\ Électricité de France DTG, Grenoble, France
}

(Manuscript received 19 August 2014, in final form 24 July 2015)

\begin{abstract}
Hydrological modeling in mountainous regions, where catchment hydrology is heavily influenced by snow (and possibly ice) processes, is a challenging task. The intrinsic complexity of local processes is added to the difficulty of estimating spatially distributed inputs such as precipitation and temperature, which often exhibit a high spatial heterogeneity that cannot be fully captured by measurement networks. Hence, an interpolation step is often required prior to the hydrological modeling step. Usually, the reconstruction of meteorological forcings and the calibration of the hydrological model are done sequentially. The outputs of the hydrological model (discharge estimates) may give some insight into the quality of the forcings used to feed it, but in this two-step independent analysis, it is not possible to easily feed the interpolation scheme back with the discrepancies between observed and simulated discharges. Yet, despite having undergone the rainfallrunoff (or snow-runoff) transformation, discharge at the outlet of a (sub)catchment is still an interesting integrator (spatial low-pass filter) of the forcing fields and is ancillary areal information complementing the direct, point-scale data collected at gauges. In this perspective, choosing the best interpolation scheme partly becomes an inverse hydrological problem. Here, a joint calibration strategy is presented where the parameters of both the interpolation model (i.e., reconstruction procedure of meteorological forcings) and the hydrological model (snow cover, soil moisture accounting, and flow-routing schemes) are jointly inferred in a multisite and multivariable approach. Interpolated fields are daily rainfall and temperature, whereas hydrological variables consist of discharge and snow water equivalent time series at several locations in the Durance River catchment.
\end{abstract}

\section{Introduction}

\section{a. Hydrological modeling in mesoscale mountain catchments}

The precise assessment of water resources in mountain regions is an important issue, as these regions truly are "water towers" for downstream, lowland regions (Viviroli and Weingartner 2008): they provide water not only for a wide range of uses such as hydropower

Corresponding author address: Nicolas Le Moine, UMR 7619 Metis, Université Pierre et Marie Curie, 4 Place Jussieu, 75252 Paris CEDEX 05, France.

E-mail: nicolas.le_moine@upmc.fr generation, irrigation, drinking water supply, and tourism, but also for ecosystems. Moreover, the knowledge of the hydrological functioning of mountain catchments is an important safety issue for flood forecasting and early warning systems in these regions.

In these regions, catchment hydrology is largely controlled by the existence of a seasonal snowpack, which delays runoff: an important part of winter precipitation falls in the solid phase and is retained on the ground until spring, where it is restituted to the hydrographic network when climate conditions allow snowmelt.

However, at the scale of a mountain catchment from a few tens to thousands of square kilometers (mesoscale), the amount of water stored in the snowpack is a very spatially heterogeneous variable. At first order, this 
heterogeneity is controlled by temperature that usually decreases with elevation. During the accumulation period, the higher the elevation, the earlier the snow starts to accumulate; conversely, during the melt period, the higher the elevation, the later the snow starts to melt.

Many other variables are heterogeneous in space: total precipitation (which usually increases with elevation; see next section), soil cover (snow will melt at a different rate in forest and on bare soil), orientation (north-facing slopes receive less incoming radiation than south-facing slopes), etc. To sum up, the evolution of snowpack configuration and hence discharge throughout the year will depend on the spatial distribution of mass and energy inputs, which are very heterogeneous in mountain regions and often poorly sampled by observational networks. As pointed out by Dettinger (2014), we are largely blind to what is happening in these high-altitude regions. There is an urgent need for a better knowledge of the water balance components and their evolution in these regions, as "we cannot adapt to something we cannot observe or predict" (p. 167). For this reason, building reliable spatial estimates of climate forcings is a key step to hydrological modeling of mountain catchments.

\section{b. Precipitation and temperature patterns in complex terrain}

In the lower regions of a well-mixed atmosphere, in which the vertical pressure profile is close to hydrostatic equilibrium, temperature will exhibit a strong, predictable decrease with elevation (Daly et al. 2008) at a lapse rate $\Gamma=-\partial T / \partial z$ ranging from $10 \mathrm{~K} \mathrm{~km}^{-1}$ (dry adiabatic lapse rate) to $3 \mathrm{~K} \mathrm{~km}^{-1}$ (moist adiabatic lapse rate), with a standard value of $6.5 \mathrm{~K} \mathrm{~km}^{-1}$. Conversely, deviations from this behavior occur when the atmosphere stratifies (e.g., in the absence of wind or in periods of weak solar heating): as a result, denser, cooler air sinks into topographic lows, producing stable temperature inversions. Since these inversions are rather the exception than the rule, especially at larger time steps (monthly to annual), the statistically robust decrease in temperature with elevation is widely used to interpolate temperature data in complex terrain, provided that we can specify realistic spatially and temporally varying lapse rates (Lundquist and Cayan 2007; Jabot et al. 2012).

The effect of elevation on precipitation patterns is far more complex and depends on the type of precipitation (stratiform or convective). In this study we will focus on the region of the southern French Alps, where most of the moisture is brought through stratiform, orographically induced precipitation events (Gottardi 2009). In such situations, the condensation rate $C\left(\mathrm{~kg} \mathrm{~m}^{-2} \mathrm{~s}^{-1}\right)$ in ascending regions upstream of the mountain ridge can be written as (see, e.g., Siler and Roe 2014):

$$
C=-\nabla \cdot(\rho q \mathbf{u}),
$$

where $\mathbf{u}$ is the horizontal velocity of the near-ground airflow layers, $\rho$ is the air density, $q$ is the specific humidity (mass of water vapor per unit mass of air), and $\nabla \cdot$ is the (two-dimensional) divergence operator. For an idealized, steady-state anelastic airflow we would have

$$
\begin{aligned}
& C \approx-\mathbf{u} \cdot \nabla(\rho q) \\
& C \approx-(\mathbf{u} \cdot \nabla z) \frac{\partial(\rho q)}{\partial z},
\end{aligned}
$$

where $z$ is the terrain elevation and $\nabla z$ its gradient vector. Equation (2) helps understand why an orographically enhanced precipitation field can be locally modeled, as a first guess, by an increasing function of elevation (at least on windward flanks). A parcel of air encountering a mountain barrier is forced to ascend with vertical velocity $w=\mathbf{u} \cdot \nabla z$ and to expand adiabatically, a process that results in the cooling of the parcel and the condensation of water vapor once the saturation is reached. Because the saturated water content $\rho q^{\text {sat }}$ decreases with elevation (due to the ClausiusClapeyron relation and the decrease in temperature with elevation), the term $-\partial \rho q / \partial z$ is positive but exponentially decreasing with elevation, with a scale height $H_{m}$ on the order of 2-4 km (Roe 2005). In contrast, because of the concave profile of mountain flanks, the slope $\|\nabla z\|$, and hence the vertical velocity $w$, usually increase as the air parcel moves closer to the mountain crest, with a usually shorter scale height. The combination of the two effects tends to produce increasing precipitation rates with elevation, though in many conditions the maximum rate will be observed in the middle of the windward flank, below the crest. On the leeward flank, temperature and precipitation patterns are controlled by adiabatic descent and evaporation (Siler and Roe 2014).

As a result of these processes and on a statistical basis, precipitation appears positively correlated with elevation, and this correlation improves as the time step becomes larger: this has led to the concept of "orographic gradient," often in a linear form, that has been used since the beginning of the twentieth century to describe and predict precipitation patterns in complex terrain (see, e.g., Alter 1919; Henry 1919; Barrows 1933; Hart 1937 for the first studies on this subject).

\section{c. Interpolation methods based on point-scale measurements}

A huge amount of literature has been published on the subject of precipitation and temperature interpolation in complex terrain, and it would be an impossible task to review all techniques and datasets here. In this section 
we rely on the review and classification proposed by Daly (2006), who classifies them into six broad categories:

- inverse distance weighting (IDW; e.g., Legates and Willmott 1990a,b; Dai et al. 1997);

- various forms of kriging, from simple kriging of raw station data to more complex procedures such as kriging with external drifts, as proposed by Goovaerts (2000);

- ANUSPLIN trivariate splines (e.g., New et al. 2002; Hijmans et al. 2005);

- local regression models such as Daymet (Thornton et al. 1997) or PRISM (e.g., Daly et al. 1994, 2002, 2003) that use a local regression function between elevation and climate at each grid cell;

- regional regression models (e.g., Brown and Comrie 2002; Johansson and Chen 2005), which in contrast use a single, domainwide, multivariate regression function between predictors (climate, latitude, longitude, elevation, wind direction, distance from the coast, etc.); and

- climatologically aided interpolation (CAI), a method that relies on the assumption that local spatial patterns of the variable being interpolated closely resemble those of an existing climate grid (sometimes called the background or predictor grid). An example of this technique would be the interpolation of monthly deviations from a mean climatology in order to produce monthly precipitation fields (see, e.g., Willmott and Robeson 1995; New et al. 2000; Funk et al. 2003; Hamlet and Lettenmaier 2005).

In particular, the simplest techniques using a lesser amount of expertise may be sensitive to the configuration of the measurement network. For example, almost no precipitation gauges are found above $2000 \mathrm{~m}$ in the Alpine environments because of the constraints of power supply (see, e.g., Gottardi 2009; Le Moine et al. 2013). Similarly, temperature stations are most often found in valley bottoms, where inversions are more likely to occur, which leads to a bias in temperature estimates at higher elevations if inversions are not explicitly accounted for in the interpolation scheme.

Whatever the method chosen, it is necessary to assess the errors in estimated values (Daly 2006). Besides internally generated model error estimates (such as in kriging), the most straightforward way to do so is cross validation: some stations are removed from the dataset in order to provide independent validation data once the interpolation process is completed. Several methods can be used to remove stations, such as jackknife (each station is removed one at a time) or stratified sample (e.g., removal of all stations in a given region or elevation range). The obvious issue with cross validation is that no error estimates can be produced at locations where no station is available.

Another independent way to evaluate precipitation datasets is to check for the water balance closure at a regional scale. Figure 1a describes this approach: first, the precipitation and temperature dataset is produced using one of the abovementioned techniques; then, the dataset is used to force one or several hydrological model(s), and the simulations are compared with several reference streamflow time series. This method has become increasingly popular since the availability of a large number of atmospheric reanalyses, precipitation downscaling products (either statistical or dynamical; e.g., Hagemann and Gates 2001; Duethmann et al. 2013; Bastola and Misra 2014), or satellite precipitation estimates. This approach can of course be extended to other hydrological diagnostic variables such as snow water equivalent measurements (e.g., Gottardi 2009). It usually provides interesting information about large-scale biases, complementary to cross-validation data. However, as mentioned earlier, in this independent analysis it is not possible to easily feed the interpolation scheme back with the discrepancies between observed and simulated streamflow time series. This can be a problem if the quality of the forcings is deemed insufficient for the applications projected.

\section{d. Areal precipitation estimates based on water balance closure with streamflow measurements}

Recognizing that streamflow measurements may be more spatially integrative and informative of actual precipitation amounts than point-scale measurements, several authors have proposed to reverse the problem and to directly infer spatial patterns of precipitation and temperature from streamflow data. Weingartner et al. (2007) use this approach to produce areal precipitation estimates on a topographic partition of Switzerland, with "mesh" elements (subcatchments) of about $150 \mathrm{~km}^{2}$. Valéry et al. (2009) use two datasets of catchments and three simple long-term water balance formulas $Q=f(P, E)$ to assess mean altitudinal precipitation gradients in Switzerland and Sweden. Using similar formulas and the notion of point-to-block or block-to-block covariances (top kriging; Skøien et al. 2006), Yan et al. (2012) perform a joint interpolation of water balance components based on precipitation gauges and streamflow data, which respects the water conservation at all levels within the hydrographical network. Kirchner (2009) uses a slightly different method based on the inversion of a storage-discharge relationship $Q=g(S)$ at the daily time step in order to infer catchment-scale precipitation in two Welsh catchments. 


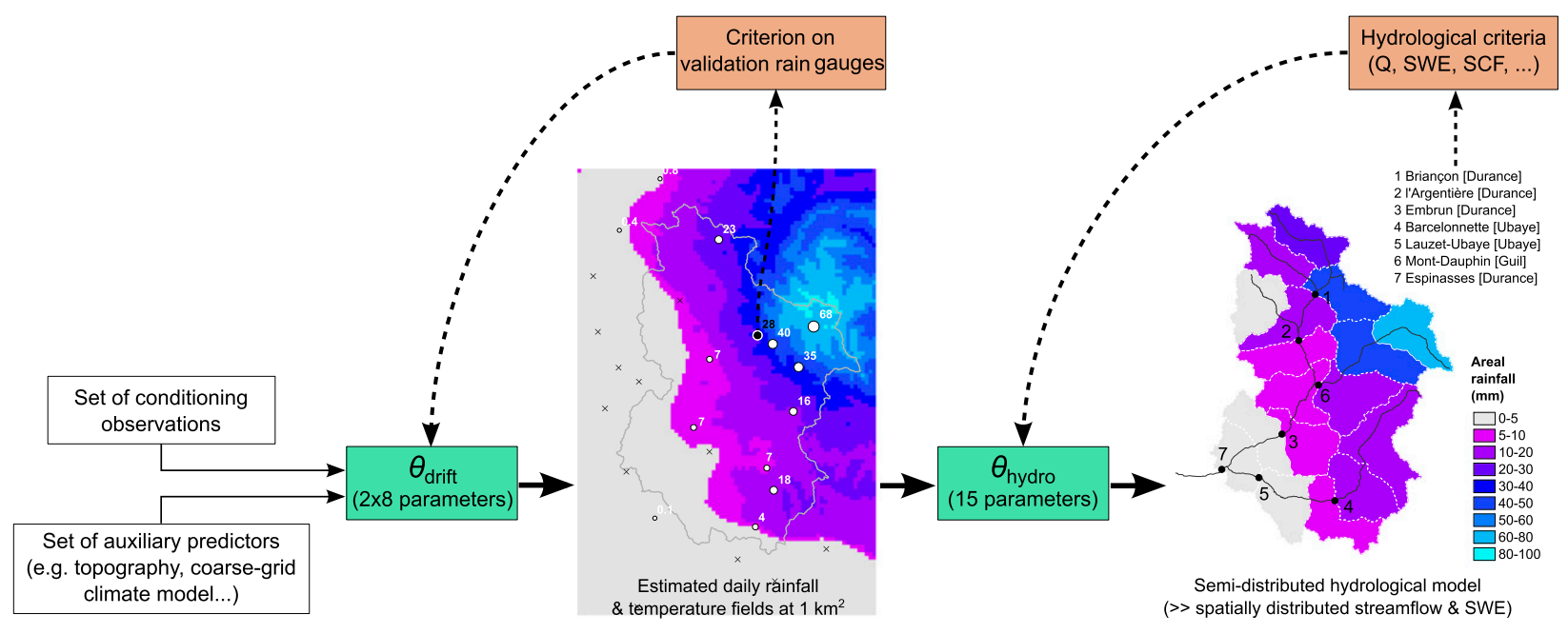

(a)

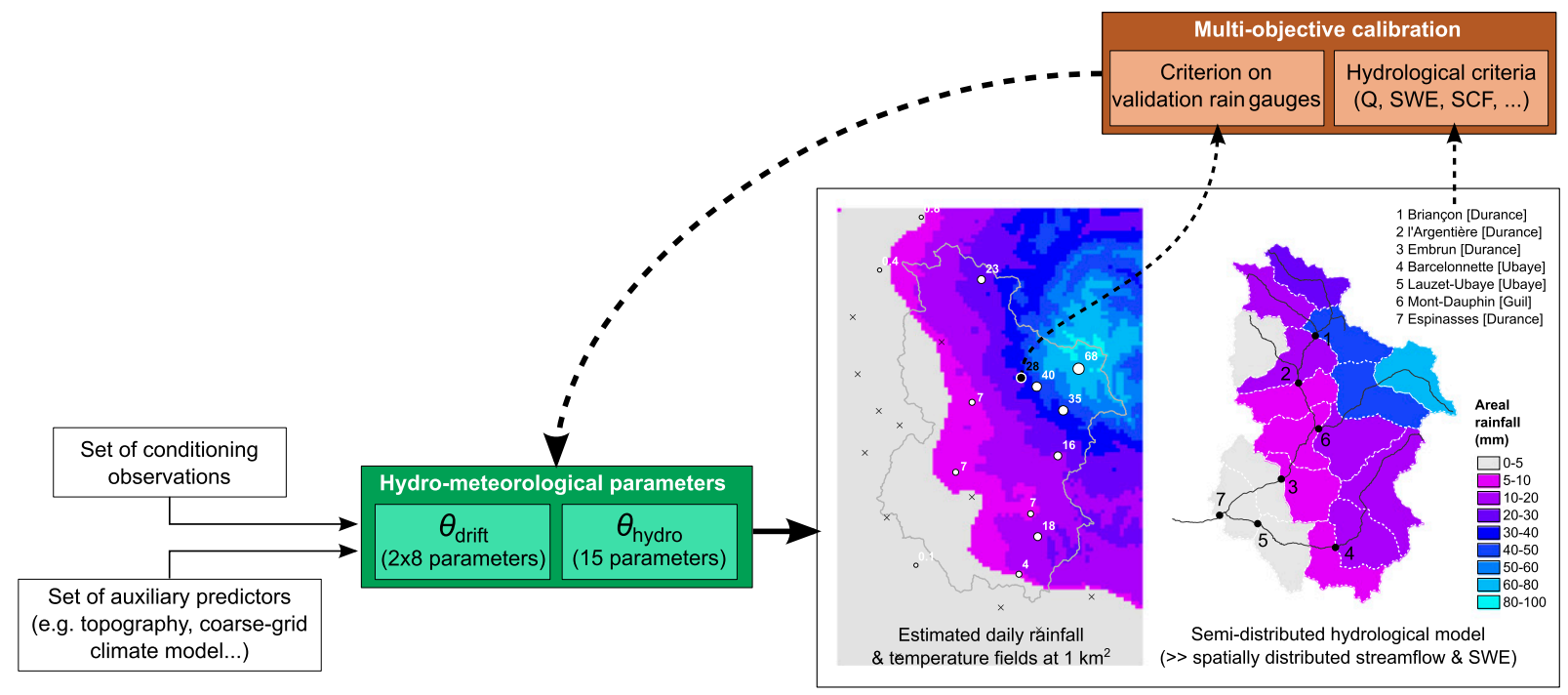

(b)

FIG. 1. Comparison of the independent vs joint calibration of hydrometeorological parameters. (a) In the independent analysis, the drift parameters $\theta_{\text {drift }}$, allowing for the estimation of precipitation and temperature fields, are first estimated on the sole basis of point-scale measurements (rain gauges and temperature stations), using, for example, a mean criterion in jackknife validation at each gauge. Then, the hydrological model is calibrated; that is, the parameter set $\theta_{\text {hydro }}$ is identified by comparing observed and simulated hydrological responses (e.g., streamflow at gauges and point-scale SWE measurements). (b) In the joint calibration, the two subsets ( $\theta_{\text {drift }}$ and $\left.\theta_{\text {hydro }}\right)$ are calibrated at once; that is, we allow the hydrological responses to inform about the values of the drift parameters $\theta_{\text {drift }}$, which was not the case in the independent analysis.

These attempts at "inverting" the hydrological cycle in order to infer catchment-scale precipitation from streamflow have so far been restricted to large time steps (usually mean annual water balance components) and/or very crude representations of the water balance (relations between precipitation $P$, evapotranspiration $E$, storage $S$, and discharge $Q$ ): these include mainly empirical, Budyko-like formulas to estimate mean annual evapotranspiration $E$ (Weingartner et al. 2007; Valéry et al. 2009; Yan et al. 2012), or monotonic storage-discharge relationships [e.g., at the daily time step in Kirchner (2009)]. These approaches give acceptable first guesses for areal precipitation as long as the errors caused by the simplifying assumptions in the rainfall-runoff relationship are of lesser importance than the uncertainties in 

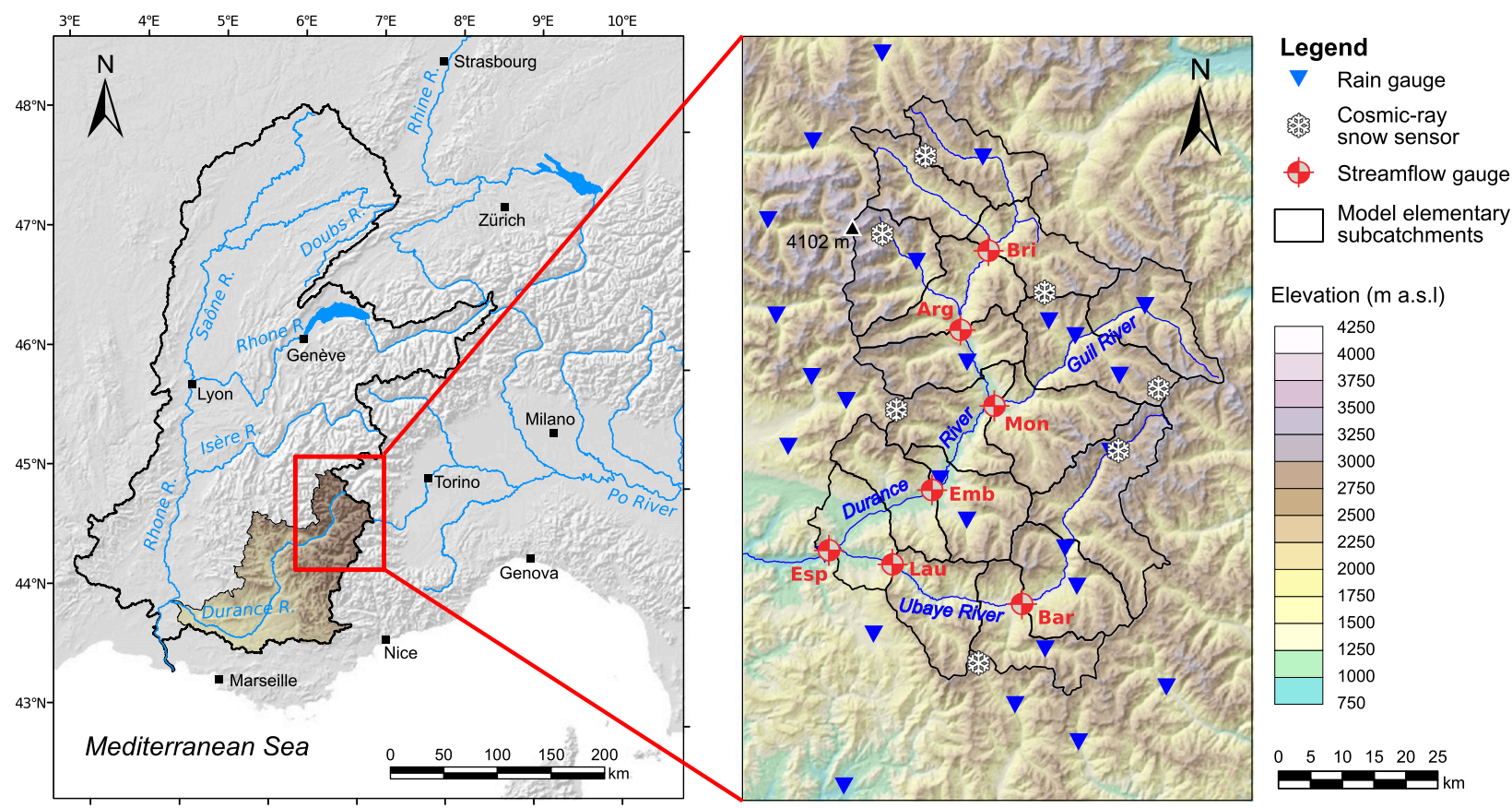

Elevation (m a.s.l)

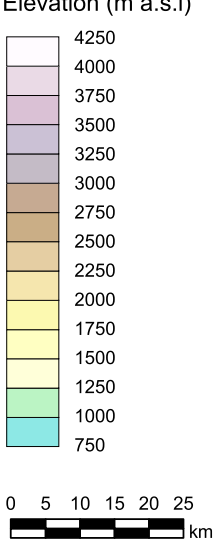

FIG. 2. Map of the upper Durance catchment. (left) Context map locating the Durance River within the Rhone River catchment. (right) Extension of the domain modeled in this study and location of precipitation, temperature, streamflow, and SWE measurements in the upper Durance catchment. Red-gray circles indicate gauging stations: Briançon (Durance River), L'Argentière-la-Bessée (Durance River), Mont-Dauphin (Guil River), Embrun (Durance River), Barcelonnette (Ubaye River), Lauzet-Ubaye (Ubaye River), and Espinasses (Durance River).

the precipitation input. They are related to climatologically aided interpolation in that the "background" or "predictor" is the field $P=f^{-1}(Q, E)$ given by the analytical inversion of the simple water balance model.

However, it is clear that these approaches are not well suited for finer time scales and/or catchments with more complex hydrological functioning such as snowdominated catchments. Moreover, they do not give access to subgrid variability, that is, the variability inside the (sub)catchments used for deconvoluting the rainfall-runoff relationship: since they invert lumped formulations relating the areal rainfall to the streamflow at the outlet, it is not possible to produce gridded precipitation datasets.

\section{e. Objective of this study}

In this paper we show that the idea of hydrological inversion-or hydrologically aided interpolation (HAI) - is applicable on a daily basis using a full hydrological model, in order to produce gridded, daily precipitation and temperature fields. In section 2, we present the Durance River dataset used for this study. Then in section 3, we present the geostatistical model used to produce gridded daily precipitation and temperature fields using point-scale measurements. The purpose of the paper is not to introduce a state-of-the art model for the orographic dependency of precipitation and temperature: the objective is rather to propose a methodology to help identify the parameters of such a model, whatever its formulation. In section 4 we first present the hydrological model used to solve the direct problem (i.e., producing streamflow estimates with the knowledge of spatially distributed daily forcings). Then, we present the calibration procedure allowing for the joint identification of both the precipitation and temperature gradients (subset of parameters denoted $\theta_{\text {drift }}$ in Fig. 1) and of the hydrological model's parameters (denoted $\theta_{\text {hydro }}$ ). It is a stochastic inversion procedure using a multiobjective evolutionary algorithm (MOEA). Section 5 presents the results of the procedure in the Durance River catchment and gives the proof of concept that the parameters of a precipitation and temperature interpolation scheme are better identified when the interpolation is hydrologically constrained. We show that, using this multiobjective framework, it is possible to take advantage of measurements having very different spatial support (Clark et al. 2011) in order to constrain the model's behavior both at local and mesoscale. In the conclusions (section 6), we sum up our findings and give perspectives on future applications. 


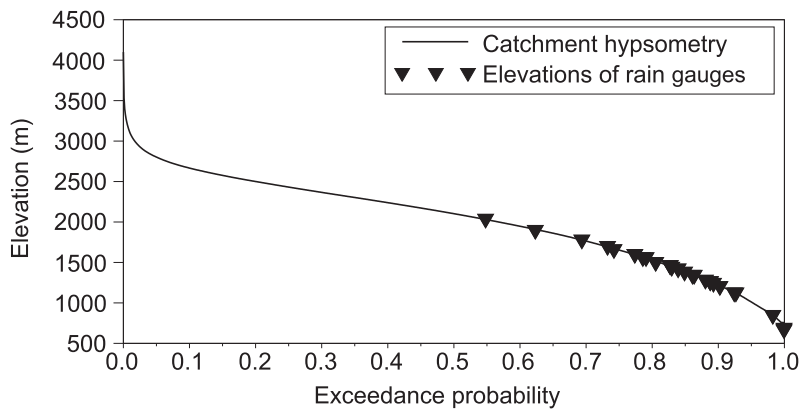

FIG. 3. Hypsometric curve of the upper Durance catchment. The quantiles corresponding to the elevations of the rain gauges are plotted with triangles. We can see that the highest rain gauge at $2031 \mathrm{~m}$ corresponds to a probability of exceedance of 0.55 , which means that the highest $55 \%$ of the catchment has no observations at all.

\section{Study area: The upper Durance catchment}

The Durance River is a left-bank (eastern) tributary of the Rhone River and rises in the southern Alps near the French-Italian border, as illustrated in Fig. 2. The catchment has an area of $14000 \mathrm{~km}^{2}$ at the confluence with the Rhone River next to the city of Avignon (a few kilometers before it flows into the Mediterranean Sea), making it its last major tributary. In this study, we focus on the Alpine part of the Durance River catchment, upstream from the large Serre-Ponçon hydropower dam and its lake $\left(1.3\right.$ billion $\left.\mathrm{m}^{3}\right)$. This catchment has an area of $3580 \mathrm{~km}^{2}$ with a mean annual discharge of $79 \mathrm{~m}^{3} \mathrm{~s}^{-1}$; it has a strongly snow-dominated function, with peak discharges occurring in May and June and low flows occurring during winter.

The elevation ranges from $756 \mathrm{~m}$ at the Espinasses gauging station to $4102 \mathrm{~m}$ at the Barre des Écrins (the most southerly four-thousander in Europe). Some small glaciers are located in the Écrins range in the west of the catchment, such as the Glacier Blanc $\left(6 \mathrm{~km}^{2}\right)$ and the Glacier Noir $\left(4.5 \mathrm{~km}^{2}\right)$. Figure 3 shows the hypsometric curve of the catchment.

In this study we use a dataset of 26 rain gauges and six temperature stations belonging to Électricité de France and Météo France observational networks over the period 1981-2004. The configuration of the stations is typical of observational networks in mountain areas: there is approximately one rain gauge per $150 \mathrm{~km}^{2}$ and none above $2000 \mathrm{~m}$ in elevation. The elevations of the 26 gauges are plotted on the hypsometric curve in Fig. 3: we can see that the 2000-m limit roughly corresponds to the median elevation, which means that the upper half of the catchment, which is the part receiving the most precipitation, is not monitored at all.

Streamflow data at the outlet (Espinasses) and at six internal subcatchments are provided by Électricité de France and the French Ministry for Environment (see
TABLE 1. Gauging station summary.

\begin{tabular}{lccc}
\hline \hline Gauging station & River & Area $\left(\mathrm{km}^{2}\right)$ & $\begin{array}{c}\text { Mean discharge } \\
\text { 1981-2004 }\left(\mathrm{m}^{3} \mathrm{~s}^{-1}\right)\end{array}$ \\
\hline Briançon & Durance & 548 & 13.4 \\
L'Argentière- & Durance & 984 & 26.7 \\
$\quad$ la-Bessée & & & \\
Mont-Dauphin & Guil & 723 & 12.1 \\
Embrun & Durance & 2170 & 50.9 \\
Barcelonnette & Ubaye & 549 & 10.1 \\
Lauzet-Ubaye & Ubaye & 946 & 20.3 \\
Espinasses & Durance & 3580 & 78.6 \\
\hline
\end{tabular}

Table 1): four of them are located on the main stream of the Durance River (Briançon, L'Argentière-la-Bessée, Embrun, and Espinasses) while the others are located on tributaries: the Ubaye River (Barcelonnette and LauzetUbaye) and the Guil River (Mont-Dauphin). We also use snow water equivalent time series measured at seven cosmic-ray snow sensors operated by Électricité de France and located at various elevations: Cézanne (1877 m), Passaur (2002 m), Sanguinière (2058 m), Izoard (2275 m), Chardonnet (2438 m), Prapic (2492 m), and Les Marrous (2685 m).

\section{Geostatistical model formulation for daily precipitation and temperature fields}

\section{a. Weather typing}

In this study we use a precipitation and temperature interpolation scheme based on a weather typing approach. We will assume that precipitation (temperature) fields occurring on days having a similar atmospheric circulation pattern at the synoptic scale will share common properties such as orographic gradients (temperature lapse rate), correlation length between stations, etc. This study is based on the classification in use at Électricité de France Division Technique Générale (DTG; see, e.g., Paquet et al. 2006; Garavaglia et al. 2010), which comprises eight weather patterns (WPs), defined according to the pattern of geopotential height at 700 and $1000 \mathrm{hPa}$. Figure 4 illustrates the typical synoptic situation $(1000 \mathrm{hPa}$ only) for each WP, and Table 2 sums up the statistics of occurrence of these situations. Table 2 also shows the mean precipitation amounts at the gauges in each weather pattern: it can be seen that the patterns that bring the most precipitation are WPs 1, 2, 4, and 7.

\section{b. Formulation of the precipitation model}

\section{1) Requirements AND RAtionale}

The objective of this study is to demonstrate the potential of using different categories of observations (rain gauges, SWE measurements, and streamflow data) to help assess precipitation elevation gradients and temperature 

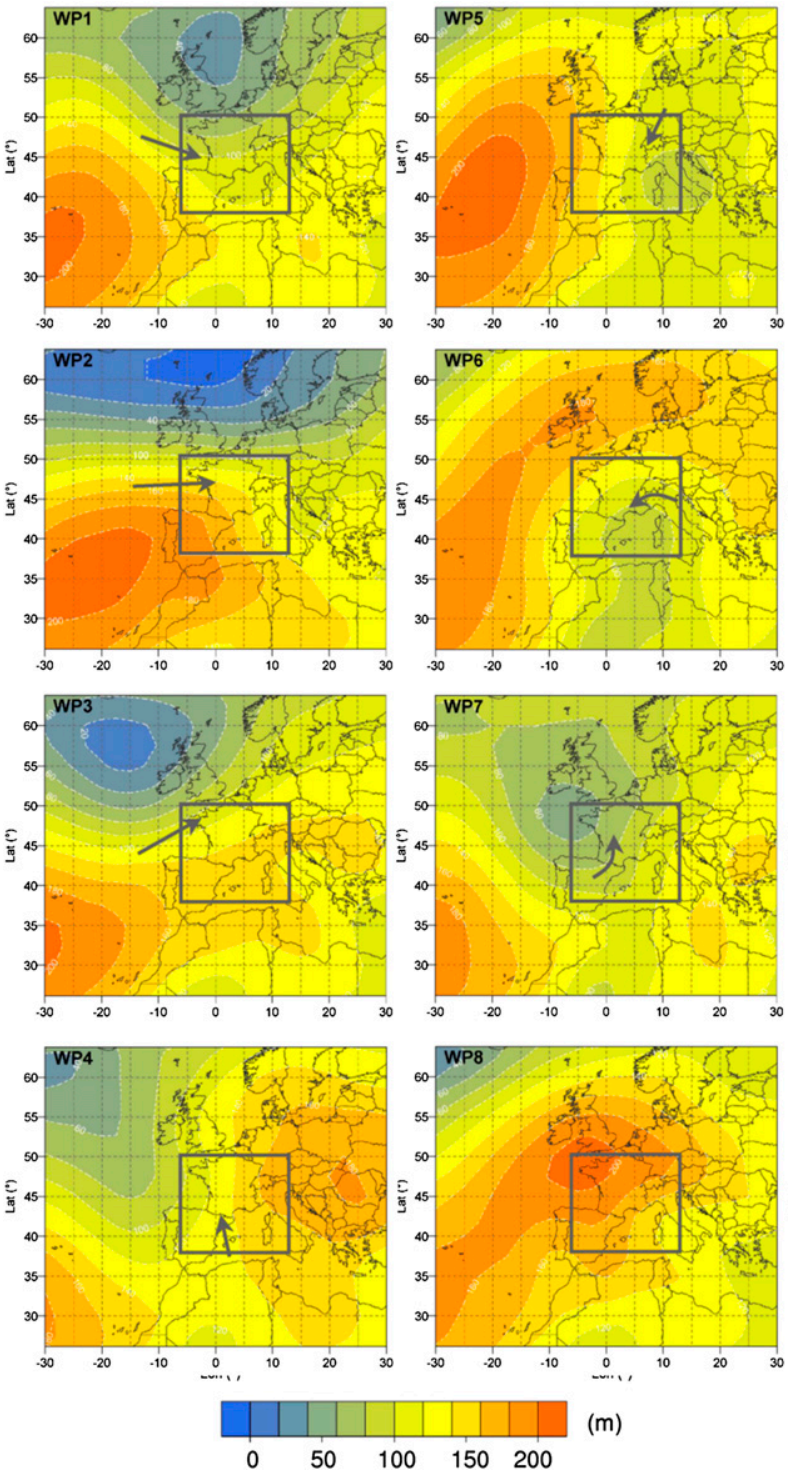

FIG. 4. Maps of the average geopotential height at $1000 \mathrm{hPa}$ (m) for (top left) WP 1 to (bottom right) WP 8 (adapted from Garavaglia et al. 2010). The color scale runs from 0 (dark blue) to $>200$ (orange). Arrows indicate the atmospheric flow of low layers, and the rectangle indicates the window in which the distance between geopotential fields is computed.

lapse rates (drift parameters). The main difficulty-but also the interest-is that these observations have very different spatial supports (or representative scales): rain gauge data and SWE measurements have a very small spatial support (nearly a point). On the contrary, a streamflow measurement has a very large spatial support: this support is the catchment. Hence, if we want to make use of all these observations, we have to be able to produce acceptable temperature and precipitation forcings at very different support sizes. At the point scale, we need correct temporal mean and variance, correct number of zero-precipitation days (e.g., for comparison with jackknife rain gauges), correct correlation (e.g., for simulating snow accumulation episodes at SWE gauges), etc. At the catchment scale, we need unbiased areal precipitation estimates (i.e., volumes) in order to force the hydrological model. Hence, we need correct spatial statistics for each event, such as spatial mean and variance, spatial intermittence (fractional area which receives no precipitation at all), etc. At this scale, the orographic enhancement is only a statistical effect, because on a given day there is no monotonic relationship between elevation and precipitation amount: it depends on where the precipitation event occurs in the first place.

The rationale behind the precipitation model presented hereafter is to decompose each daily field into two parts, with each part satisfying one of the previous requirements.

The first is a deterministic part (called the template), with low spatial frequency, which will ensure that areal precipitation estimates are unbiased at large temporal and spatial scales (seasonal-catchment scale). This template field is not random and contains deterministic effects that need to be explicitly modeled. In mountain terrain, a dominant effect is orographic enhancement, which can be modeled at first order with a monotonic function of elevation (e.g., linear, exponential). This effect is better modeled with a weather pattern approach, because precipitation gradients depend at first order on the direction and intensity of the synoptic atmospheric circulation as it encounters the mountain range [Eq. (2)], that is, the faster the circulation, the higher the gradient.

The second is a stochastic part (called the scaling factor), with high spatial frequency, which will ensure acceptable statistics at small spatial and temporal scales (point-event scale).

The decomposition used in this study is illustrated in Fig. 5. On a given day $j$ belonging to weather pattern $\mathrm{WP}(j)$, we write the precipitation amount at location $\mathbf{x}$ as

$$
P(\mathbf{x}, j)=P_{\mathrm{WP}(j)}^{*}(\mathbf{x}) \Lambda(\mathbf{x}, j) .
$$

The daily precipitation field is thus seen as a "mean" realization (or template field; Fig. 5c) for the weather pattern $\mathrm{WP}(j), P_{\mathrm{WP}(j)}^{*}(\mathbf{x})$, deformed by a local scaling factor $\Lambda(\mathbf{x}, j)$ (Fig. 5e). The template is itself the product of a deterministic drift/trend (Fig. 5a) and of a stochastic part (Fig. 5b). It is a rather smooth field (it does not have the variance of an actual daily precipitation field) without spatial intermittence and is meant to embed as many deterministic effects as possible (such as orographic forcing, represented by the deterministic drift). Conversely, the field $\Lambda(\mathbf{x}, j)$ may exhibit spatial intermittence.

The product of the two parts gives the estimated precipitation (Fig. 5f) field for each day. If the decomposition 
TABLE 2. Yearly and seasonal statistics of occurrence for the eight WPs for the period 1981-2004 and related precipitation statistics on the network of 26 precipitation gauges used in this study.

\begin{tabular}{|c|c|c|c|c|c|c|c|c|}
\hline \multirow[b]{2}{*}{ Class } & \multirow[b]{2}{*}{ WP name } & \multicolumn{5}{|c|}{ Occurrence statistics (\%) } & \multicolumn{2}{|c|}{$\begin{array}{l}\text { Mean amount } \\
(\mathrm{mm})\end{array}$} \\
\hline & & Year & Winter & Spring & Summer & Autumn & Daily & Yearly \\
\hline WP 1 & Atlantic wave & 7.6 & 4.7 & 7.2 & 11.1 & 7.3 & 5.9 & 164 \\
\hline WP 2 & Steady oceanic & 23.8 & 38.0 & 21.4 & 12.2 & 23.8 & 2.1 & 183 \\
\hline WP 3 & Southwest circulation & 7.8 & 4.9 & 6.8 & 11.5 & 7.7 & 2.6 & 74 \\
\hline WP 4 & South circulation & 18.4 & 20.0 & 19.8 & 11.0 & 23.0 & 2.6 & 175 \\
\hline WP 5 & Northeast circulation & 5.9 & 6.4 & 7.2 & 5.2 & 4.8 & 1.8 & 39 \\
\hline WP6 & East return & 5.6 & 4.7 & 7.6 & 5.6 & 4.7 & 4.7 & 96 \\
\hline WP 7 & Central depression & 3.6 & 2.1 & 4.0 & 3.6 & 4.6 & 10.4 & 137 \\
\hline WP 8 & Anticyclonic & 27.3 & 19.3 & 26.0 & 39.8 & 23.9 & 0.6 & 61 \\
\hline
\end{tabular}

is correct (notably, if the drift parameters controlling the orographic enhancement are correctly estimated), the previous requirements should be met, that is, we would should have acceptable temporal and spatial statistics on a wide range of scales/supports (from point scale to catchment scale, and from event scale to seasonal or annual scale). Figure 6 illustrates the transformation of the daily map into areal estimates, used as inputs in the semidistributed hydrological model.

In the following sections, we give some details about the mathematical formulation of the model. Indeed, the joint calibration strategy strongly relies on the ability of the interpolation model to meet the aforementioned requirements: for this reason, it seems important to give some insight into this model. In our opinion, the one presented here is an attempt of minimal complexity to meet all the requirements; it is clearly not the only possible one. We only present the main statistical hypotheses: numerical details and algebra are provided in the appendix. Bold symbols usually denote vectors; as much as possible, random variables are denoted with a capital letter and realizations of this random variable are denoted in lowercase [e.g., $\lambda(\mathbf{x})$ will denote a realization of the random field $\Lambda$ at location $\mathbf{x}$ ]. Tilded symbols denote estimated values (expected values for random variables).

\section{2) ESTIMATION OF THE PRECIPITATION TEMPLATE FOR EACH WEATHER PATTERN}

Given the properties mentioned above, we chose a loglinear model to represent the orographic enhancement of precipitation in weather pattern $k$, that is, we have locally

$$
\left.\frac{d P_{k}^{*}}{P_{k}^{*}}\right|_{\mathbf{x}_{0}}=\left.d\left(\ln P_{k}^{*}\right)\right|_{\mathbf{x}_{0}}=\alpha_{k} d z .
$$

The SI unit for the increase rate $\alpha_{k}$ is $\mathrm{m}^{-1}\left(1 / \alpha_{k}\right.$ is a scale height), but for the sake of clarity we will express it in percent of increase every $100 \mathrm{~m}\left(\% \mathrm{hm}^{-1}\right)$.

We perform a kriging with an external drift (KED) with elevation $z(\mathbf{x})$ as an auxiliary variable in order to get an estimation of $\ln P_{k}^{*}\left(\mathbf{x}_{0}\right)$ at an ungauged location $\mathbf{x}_{0}$, given the values $p_{k}^{*}\left(\mathbf{x}_{1}\right), \ldots, p_{k}^{*}\left(\mathbf{x}_{n}\right)$ at the $n$ conditioning rain gauges:

$$
\begin{aligned}
& \ln P_{k}^{*}\left[\mathbf{x}_{0} \mid p_{k}^{*}\left(\mathbf{x}_{1}\right), \ldots, p_{k}^{*}\left(\mathbf{x}_{n}\right) ; \alpha_{k}\right] \\
& \quad=b_{k}+\alpha_{k} z\left(\mathbf{x}_{0}\right)+\mu_{\mathrm{KED}, k}\left(\mathbf{x}_{0}\right)+\sigma_{\mathrm{KED}, k}\left(\mathbf{x}_{0}\right) U\left(\mathbf{x}_{0}\right),
\end{aligned}
$$

where $p_{k}^{*}\left(\mathbf{x}_{i}\right)$ is the mean daily precipitation amount at gauge location $\mathbf{x}_{i}$ computed on all days of weather pattern $k, U$ is a standard Gaussian random variable, and

$$
\mu_{\mathrm{KED}, k}\left(\mathbf{x}_{0}\right)=\sum_{i} w_{i}\left(\mathbf{x}_{0}\right)\left[\ln p_{k}^{*}\left(\mathbf{x}_{i}\right)-\alpha_{k} z\left(\mathbf{x}_{i}\right)\right]
$$

is the simple kriging estimate of the detrended field (stochastic part of the template, Fig. 5b) at location $\mathbf{x}_{0}$. The value of the template at location $\mathbf{x}_{0}$ is then given by the expected value

$$
\begin{aligned}
\tilde{p}_{k}^{*}\left(\mathbf{x}_{0}\right)= & \mathbb{E}\left\{P_{k}^{*}\left[\mathbf{x}_{0} \mid p_{k}^{*}\left(\mathbf{x}_{1}\right), \ldots, p_{k}^{*}\left(\mathbf{x}_{n}\right)\right]\right\} \\
= & \exp \left[b_{k}+\alpha_{k} z\left(\mathbf{x}_{0}\right)\right. \\
& \left.+\mu_{\mathrm{KED}, k}\left(\mathbf{x}_{0}\right)\right] \exp \left[\frac{1}{2} \sigma_{\mathrm{KED}, k}^{2}\left(\mathbf{x}_{0}\right)\right],
\end{aligned}
$$

where the correcting factor $\exp \left[(1 / 2) \sigma_{\mathrm{KED}, k}^{2}\right]$ comes from the fact that the expectation of the raw variable is not the exponential of the expectation of its logarithm.

\section{3) ESTIMATION OF THE LOCAL SCALING FACTOR FOR EACH DAY}

As mentioned at the beginning of section $3 b$, handling the local scaling factor $\lambda(\mathbf{x}, j)$ is more complicated 


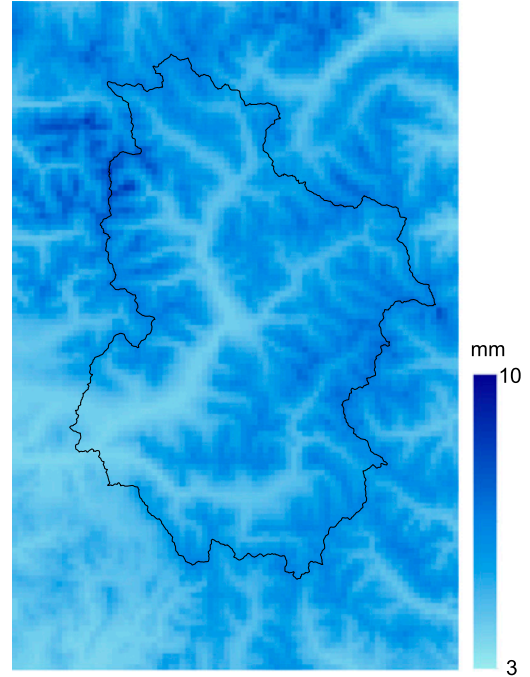

(a) Drift for WP6

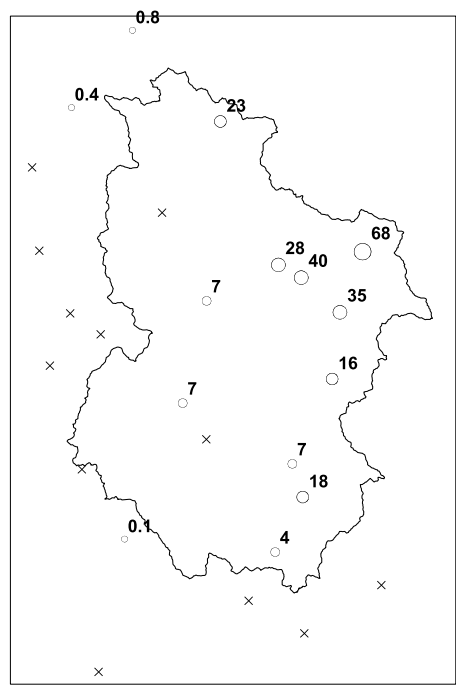

(d) Observed daily values on 1993-03-01

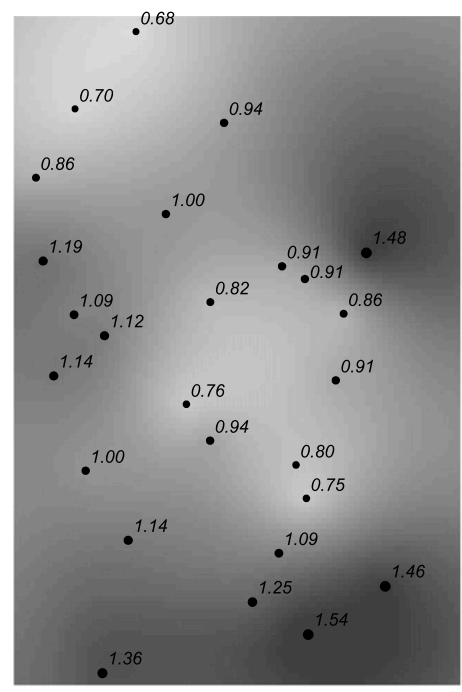

(b) Residual to drift for WP6

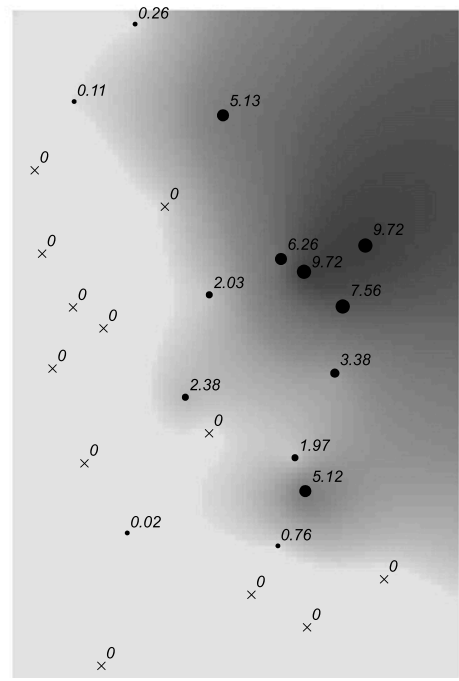

(e) Daily residual to WP6 template

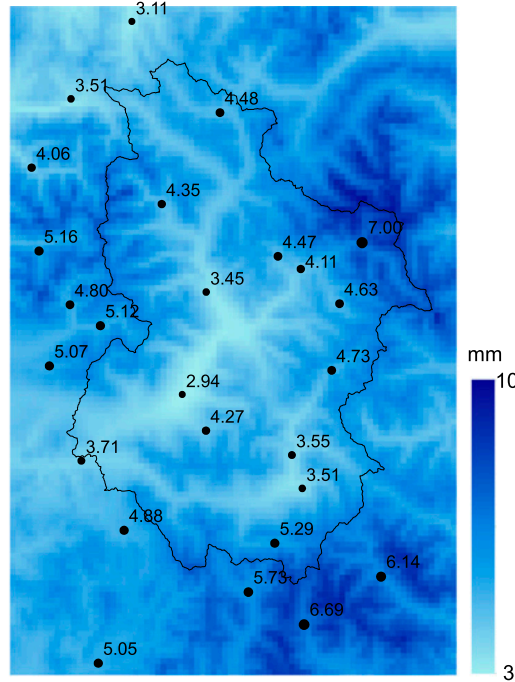

(c) Template for WP6

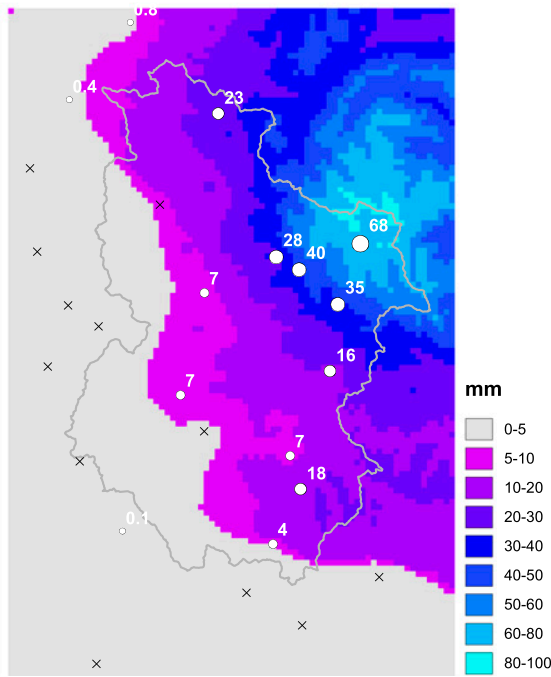

(f) Daily precipitation field on 1993-03-01

FIG. 5. Construction of a daily rainfall field: example of 1 Mar 1993, belonging to WP 6 (East return). The procedure consists of five steps: (a) construction of the drift for WP 6; (b) lognormal kriging of the residuals to the drift based on multiplicative residuals observed at the gauges; (c) construction of the template for WP 6, which is the product of (a) and (b); (e) kriging of the daily residuals to the template; and (f) construction of the daily field, which is the product of (c) and (e). Grid size is $1 \mathrm{~km} \times 1 \mathrm{~km}$, and the domain shown is $80 \mathrm{~km} \times 120 \mathrm{~km}$ (9600 grid points).The color scale runs from 0-5 (gray) to 80-100 (cyan) mm.

because of the spatial intermittence of this field: the cumulative distribution function (CDF) of $\Lambda$ may have an atom at zero (i.e., the discrete value $\lambda=0$ may have a strictly positive probability of occurrence). In the following, we will omit the subscript $j$ for the sake of clarity, but the estimation of the field has to been done for each day. Since the actual precipitation amount and the value of the template for day $j$ are known at the gauging locations $\mathbf{x}_{1}, \ldots, \mathbf{x}_{n}$, we have the set of conditioning values $\lambda\left(\mathbf{x}_{1}\right), \ldots, \lambda\left(\mathbf{x}_{n}\right)$. We will build a
Gaussian transformation of $\Lambda$, that is, a function $\phi$ such that

$$
Y\left(\mathbf{x}_{0}\right)=\phi\left[\Lambda\left(\mathbf{x}_{0}\right)\right]
$$

is a Gaussian random variable. This transformation relies on the following hypotheses:

1) the rate of spatial intermittence $f_{0}$ can be estimated by the proportion of nonrainy gauges; 


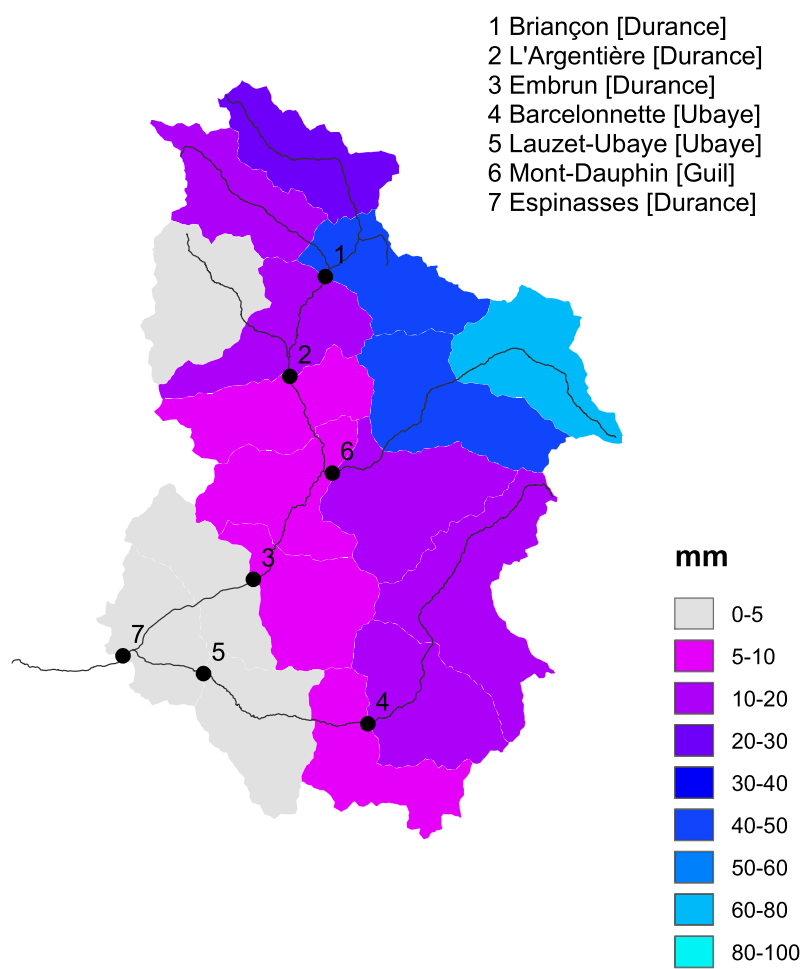

FIG. 6. Daily areal rainfall (zonal mean) for the 17 mesh elements for 1 Mar 1993 (same day as in Fig. 5). Control nodes (hydrometric gauging sites) are displayed with black dots, and main streams are drawn with solid black lines. The color scale runs from 0-5 (gray) to 80-100 (cyan) mm.

2) the local scaling factor in the rainy part of the field follows a lognormal distribution; and

3) the location and scale parameters $\mu$ and $\sigma$ of this lognormal distribution are related or, equivalently, there is a functional relation between the mean and the variance of the nonzero part of the field $\Lambda$ : $\sigma_{\Lambda^{+}}^{2}=g\left(\mu_{\Lambda^{+}}\right)$.

\section{4) MEAN-VARiance RELATIONShiP}

Hypothesis 3 is very important, as a strong decreasing relationship between the mean and the coefficient of variation of $\Lambda$ appears in the data for all weather patterns. It basically says that if the average value of the daily field is smaller than the average value of the template, we may have locally very high or low values of the scaling factor. Conversely, if the average value is much higher than the average of the template, it is likely that the scaling factor is quite uniform and that the daily field is more or less homothetic to the template (by a factor greater than 1). We will use this property to get robust estimates of the parameters $\mu$ and $\sigma$ describing the lognormal distribution of nonzero values, on the basis of the mean scaling factor $\mu_{\Lambda}$.
According to the hypotheses, we have $\mu_{\Lambda^{+}}=$ $\mathbb{E}[\Lambda \mid \Lambda>0]=e^{\mu+\left(\sigma^{2} / 2\right)}$. For the variance, we have $\sigma_{\Lambda^{+}}^{2}=\mathbb{V}[\Lambda \mid \Lambda>0]=\left(e^{\sigma^{2}}-1\right) \mu_{\Lambda^{+}}^{2}$.

Inverting this formula and expressing $\sigma_{\Lambda^{+}}^{2}$ as a function of $\mu_{\Lambda^{+}}^{2}$ yields

$$
\left\{\begin{array}{l}
\sigma^{2}=\ln \left[1+\frac{g\left(\mu_{\Lambda^{+}}\right)}{\mu_{\Lambda^{+}}^{2}}\right] \\
\mu=\ln \left(\mu_{\Lambda^{+}}\right)-\frac{\sigma^{2}}{2}
\end{array}\right.
$$

If on a given day we have only a few gauging sites with nonzero rainfall-let us say 3 in $n$, for example-we do not need to compute the mean and variance of the logarithm of the three scaling factors in order to estimate $\mu$ and $\sigma$ for that day: a more robust guess is found by computing only the mean cumulate $\mu_{\Lambda^{+}}$ on the three points and using the mean-variance relationship.

For a given weather pattern, we fit a relationship $\sigma_{\Lambda^{+}}^{2}=g\left(\mu_{\Lambda^{+}}\right)$in the form

$$
g\left(\mu_{\Lambda^{+}}\right)=\frac{c\left(\frac{\mu_{\Lambda^{+}}}{\beta}\right)^{\gamma}}{1+\left(\frac{\mu_{\Lambda^{+}}}{\beta}\right)^{\gamma-\delta}}, \quad c>0, \quad \beta>0, \quad \gamma>2, \quad \delta<2 .
$$

This form ensures that the coefficient of variation $\sigma_{\Lambda^{+}} / \mu_{\Lambda^{+}}$remains bounded when $\mu_{\Lambda^{+}} \rightarrow 0$ and decreases when $\mu_{\Lambda^{+}}$increases. In log-log coordinates, the plot $\sigma_{\Lambda^{+}}^{2}$ versus $\mu_{\Lambda^{+}}$clearly shows two asymptotes with distinct slopes $\gamma>2$ and $\delta<2$ (see Fig. 7 for WP 1).

\section{c. Gaussian transformation and kriging of the Gaussian field}

Now that we have described the $\operatorname{CDF} F_{\Lambda}$ of $\Lambda$, we can use the transformation

$$
\Lambda=F_{\Lambda}^{-1}\left[\mathscr{N}_{0,1}(Y)\right] \quad \Leftrightarrow \quad Y=\mathscr{N}_{0,1}^{-1}\left[F_{\Lambda}(\Lambda)\right],
$$

where $\mathscr{N}_{0,1}$ is the CDF of the standard normal distribution. The procedure is illustrated in Fig. 8. However, problems may arise for computing the transformation $Y=\left(\mathscr{N}_{0,1}^{-1} \circ F_{\Lambda}\right)(\Lambda)$. Indeed, since $F_{\Lambda}$ has an atom at zero (i.e., the discrete value $\lambda=0$ has a strictly positive probability) in case of spatial intermittence, then $F_{\Lambda}^{-1}$ is not injective, and the image of $\lambda=0$ is the whole segment $\left[0, f_{0}\right]$.

Once we have estimated the structural function (semivariogram) of $Y$ using nonzero data, we generate Gaussian samples at locations where the rainfall amount 


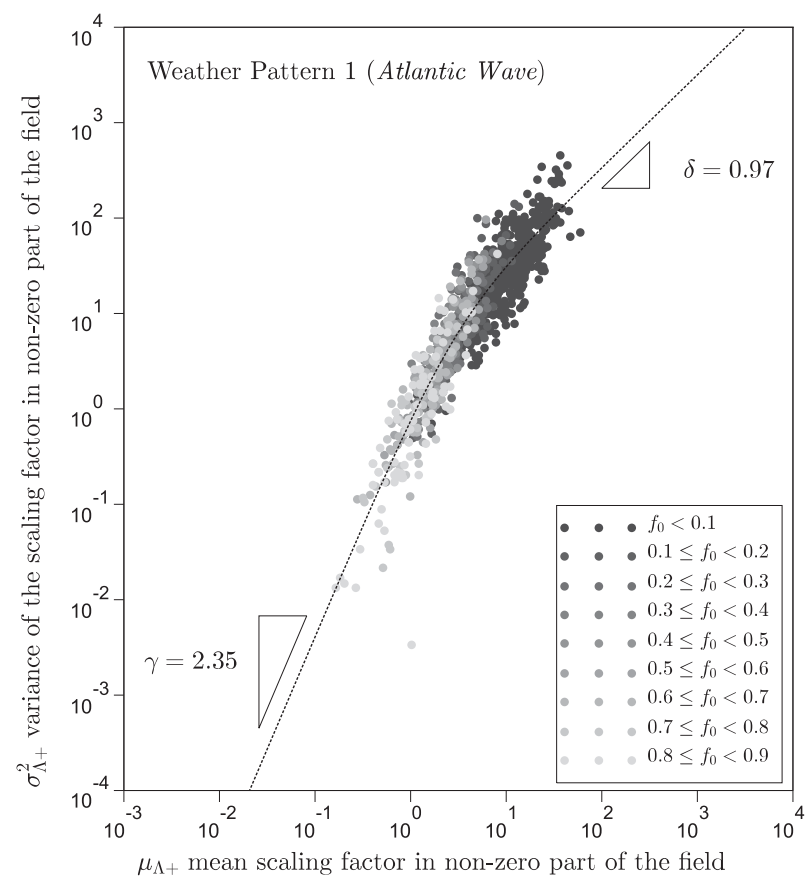

FIG. 7. Mean-variance relationship in daily scaling factor fields. Each dot represents a day and the shade of gray indicates the intermittence $f_{0}$ of the field on that day. Days with less than four nonzero gauges are not displayed. The gray scale runs from $f_{0}$ between 0.8 and 0.9 (lightest shade) to $<0.1$ (darkest shade) in 0.1 increments.

is zero using a Gibbs sampling procedure (adapted from, e.g., Vischel et al. 2009). This procedure is described in the appendix.

\section{EXPECTATION OF THE LOCAL SCALING FACTOR}

Once we have generated Gaussian samples at every conditioning location, we can estimate the distribution of $Y\left(\mathbf{x}_{0}\right)$ at an ungauged location by ordinary kriging using the values $y\left(\mathbf{x}_{1}\right), \ldots, y\left(\mathbf{x}_{n}\right)$ : it is a Gaussian distribution with mean $\mu_{\mathrm{SK}}\left(\mathbf{x}_{0}\right)$ and variance $\sigma_{\mathrm{SK}}^{2}\left(\mathbf{x}_{0}\right)$ [Fig. 9, probability density function (PDF) in gray in the top panel].

The expectation of the (untransformed) local scaling factor is then given by the following integral:

$$
\begin{aligned}
\tilde{\lambda}\left(\mathbf{x}_{0}\right) & =\mathbb{E}\left[\Lambda\left(\mathbf{x}_{0}\right) \mid \lambda\left(\mathbf{x}_{1}\right), \ldots, \lambda\left(\mathbf{x}_{n}\right)\right] \\
& =\int_{-\infty}^{+\infty} \phi^{-1}(y) \frac{1}{\sigma_{\mathrm{SK}} \sqrt{2 \pi}} e^{-\left[\left(y-\mu_{\mathrm{SK}}\right)^{2} / 2 \sigma_{\mathrm{SK}}^{2}\right]} d y .
\end{aligned}
$$

Given the form of the direct and reverse transformations $\left(\phi\right.$ and $\left.\phi^{-1}\right)$, this expectation does not have a closed form. It can nonetheless be estimated very quickly using a quadrature formula (see the appendix).

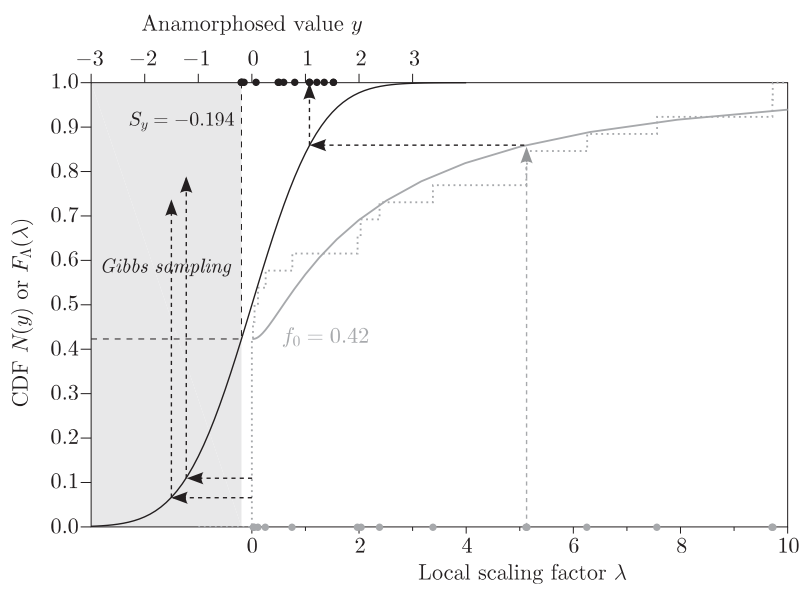

FIG. 8. Construction of a Gaussian transformation of the daily local scaling factor. First, the lognormal distribution of nonzero scaling factors is estimated using the mean $\mu_{\Lambda}$ and intermittence rate $f_{0}$ of the sampled field and the mean-variance relationship presented in section 4 (the empirical CDF is shown in dotted gray but is not used in the computations). Then, the values at the $n$ conditioning rain gauges $\lambda\left(\mathbf{x}_{1}\right), \ldots, \lambda\left(\mathbf{x}_{n}\right)$ (gray dots on bottom $x$ axis) are mapped to Gaussian samples $y\left(\mathbf{x}_{1}\right), \ldots, y\left(\mathbf{x}_{n}\right)$ (black dots on top $x$ axis). Where the scaling factor is 0 , a Gaussian value is obtained by Gibbs sampling. The $y$ axis runs from 0.0 to 1.0 in increments of 0.1 . The bottom $x$ axis runs from 0 to 10 in increments of 2 and the top from -3 to +3 in increments of 1 . The values in the figure are $S_{y}=-0.194$ and $f_{0}=0.42$.

\section{d. Temperature model}

We apply a similar procedure for temperature, but we use a simpler additive model without transformation: temperature is not restricted to positive values, does not span several orders of magnitude, and its CDF has no atomic component. The mean daily temperature at location $\mathbf{x}$ on day $j$ is written as the sum of a template for weather pattern $k=\mathrm{WP}(j)$ at location $\mathbf{x}$ and a local offset $\Theta(\mathbf{x}, j)$ :

$$
T(\mathbf{x}, j)=T_{\mathrm{WP}(j)}^{*}(\mathbf{x})+\Theta(\mathbf{x}, j) .
$$

The value of the template at ungauged location $\mathbf{x}_{0}$ is again obtained by kriging with an external drift using altitude as an auxiliary variable (i.e., simple kriging of the residuals to the drift):

$$
\begin{aligned}
T_{k}^{*}\left[\mathbf{x}_{0} \mid t_{k}^{*}\left(\mathbf{x}_{1}\right), \ldots, t_{k}^{*}\left(\mathbf{x}_{\mathbf{n}}\right)\right]= & b_{k}-\Gamma_{k} z\left(\mathbf{x}_{0}\right)+\mu_{\mathrm{KED}, k}\left(\mathbf{x}_{0}\right) \\
& +\sigma_{\mathrm{KED}, k}\left(\mathbf{x}_{0}\right) U\left(\mathbf{x}_{0}\right),
\end{aligned}
$$

where $\Gamma_{k}$ is the mean temperature lapse rate for weather pattern $k$ and $U$ is a standard Gaussian random variable. The value of the template at location $\mathbf{x}_{0}$ is then given by the expectation 

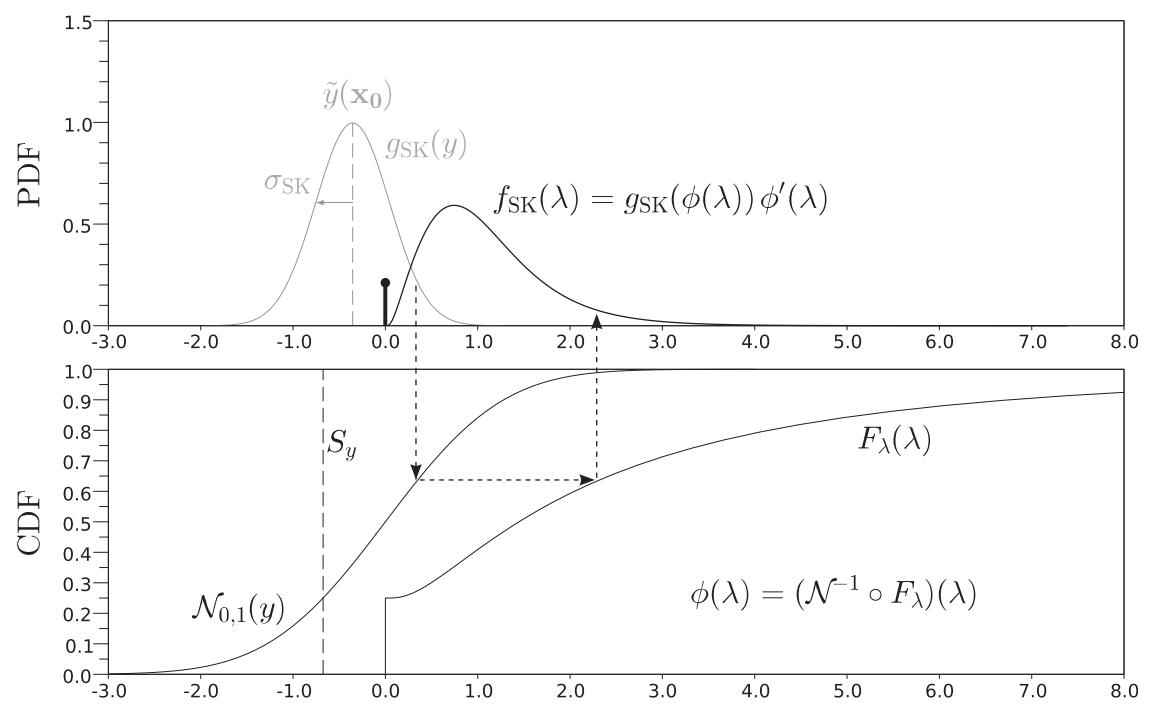

FIG. 9. Illustration of the reverse transformation. Simple kriging in the Gaussian space leads to (top) the Gaussian PDF $g_{\mathrm{SK}}(y)$ (gray). What is needed in order to get an estimate of the local scaling factor at location $\mathbf{x}_{0}$ is the expectation of the PDF $\left.f_{\mathrm{SK}}(\lambda)=g_{\mathrm{SK}}[\phi(\lambda)] \phi^{\prime}(\lambda)\right]$ (black, with an atomic value at 0 ). Given the form of $\phi$, this expectation is evaluated using a quadrature formula. The bottom part of the figure is the same as Fig. 8 .

$$
\begin{aligned}
\tilde{t}_{k}^{*}\left(\mathbf{x}_{0}\right) & =\mathbb{E}\left\{T_{k}^{*}\left[\mathbf{x}_{0} \mid t_{k}^{*}\left(\mathbf{x}_{1}\right), \ldots, t_{k}^{*}\left(\mathbf{x}_{n}\right)\right]\right\} \\
& =b_{k}-\Gamma_{k} z\left(\mathbf{x}_{0}\right)+\mu_{\mathrm{KED}, k}\left(\mathbf{x}_{0}\right) .
\end{aligned}
$$

Then, on each day the temperature field is obtained as the sum of the template field and the offset field $\Theta(\mathbf{x}, j)$, which is obtained by simple kriging of the observed offsets at the temperature stations: $\theta\left(\mathbf{x}_{1}, j\right), \ldots, \theta\left(\mathbf{x}_{n}, j\right)=t\left(\mathbf{x}_{n}, j\right)-t_{k}^{*}\left(\mathbf{x}_{n}\right)$.

As mentioned in the introduction, such a simple model is not able to reproduce temperature inversions. However, since inversions correspond to periods with stable conditions without precipitation or, more often, cold or low-sun periods without much snowmelt, the hydrological effect of missing inversions is not expected to be large.

\section{Hydrologically aided interpolation of precipitation and temperature fields}

\section{a. Hydrological model}

In this section we briefly present the hydrological model used for simulating the rainfall-runoff relationship, namely, a modified version of the CEQUEAU model currently in use at the Laboratoire National d'Hydraulique et Environnement (LNHE; Électricité de France Research and Development; see Bourqui et al. 2011). This semidistributed model is designed to run on a topographic mesh; in this study, we use 17 subcatchments with an average area of $210 \mathrm{~km}^{2}$ (Fig. 2). Only the conceptual soil moisture accounting and storage routine is taken from the original CEQUEAU scheme (Charbonneau et al. 1977). The snow routine has been replaced by a single-layer, simplified surface energy balance model and is distributed in five elevation bands in each subcatchment. The full surface energy balance (SEB) reads

$$
R_{\mathrm{sw} \downarrow}-R_{\mathrm{sw} \uparrow}+R_{\mathrm{lw} \downarrow}-R_{\mathrm{lw} \uparrow}=Q_{\mathrm{cc}, \text { snow }}+H+\mathrm{LE},
$$

where $Q_{\mathrm{cc} \text {,snow }}$ is the conductive/convective heat flux entering the snowpack. Since we do not have access to many atmospheric and aerodynamic variables, we use a strongly degraded formulation of Eq. (14) in which those unknown values are set to conceptual, timeaveraged climatological values and are calibrated. Second, we do not take turbulent fluxes $H$ and LE into account because of the lack of a robust interpolation method for wind speed and relative humidity in our model (this will be the object of future work). Finally, in order to solve more rapidly for the (conceptual) snow surface temperature $T_{\text {snow }, s}$ we linearize the longwave radiative components around a reference temperature $T_{0}$ (i.e., $T_{0}=273.15 \mathrm{~K}$ ). The resulting equation reads

$$
\begin{aligned}
& \bar{f} R_{e}-\alpha_{\text {snow }} \bar{f} R_{e}+\sigma \bar{\varepsilon}_{\text {air }} T_{0}^{4}\left(1+4 \frac{T_{\text {air }}-T_{0}}{T_{0}}\right) \\
& -\sigma T_{0}^{4}\left(1+4 \frac{T_{\text {snow }, s}-T_{0}}{T_{0}}\right)=k_{\text {snow }}\left(\frac{T_{\text {snow }, s}-T_{\text {snow }}}{2 z_{\text {snow }}}\right)
\end{aligned}
$$


TABLE 3. List of the parameters of the daily time step hydrological model. The list is divided into three parts: snow routine (14 parameters, 4 calibrated), soil moisture and deep storage routine taken from the original CEQUEAU scheme (13 parameters, 9 calibrated), and diffusive wave flow routing model (2 parameters, calibrated).

\begin{tabular}{|c|c|c|c|c|c|}
\hline No. & Symbol & Units & Description & Value/range & Optimized \\
\hline 1 & $\alpha_{\max }$ & - & Albedo of new snow & 0.9 & No \\
\hline 2 & $\alpha_{\min }$ & - & Albedo of very old snow/ice & 0.4 & No \\
\hline 3 & $\tau_{\alpha}$ & days & $\begin{array}{l}\text { Characteristic time for the decrease } \\
\text { of snow albedo with age }\end{array}$ & 35 & No \\
\hline 4 & $\bar{f}_{\mathrm{sw}}=\left\langle R_{\mathrm{sw} \downarrow} / R_{e}\right\rangle$ & - & $\begin{array}{l}\text { Climatological (time averaged) ratio } \\
\text { of incoming to extraterrestrial shortwave radiation }\end{array}$ & {$[0.4,0.8]$} & Yes \\
\hline 5 & $r_{a}$ & $\mathrm{~s} \mathrm{~m}^{-1}$ & $\begin{array}{l}\text { Aerodynamic resistance for turbulent } \\
\text { sensible heat flux }\end{array}$ & - & No \\
\hline 6 & $\lambda_{\text {snow }, 0}$ & $\mathrm{Km}^{-1} \mathrm{~s}^{-1}$ & Effective thermal conductivity of new snow & {$[0.03,0.3]$} & Yes \\
\hline 7 & $\bar{\varepsilon}_{\text {air }}$ & - & $\begin{array}{l}\text { Climatological (time averaged) effective emissivity } \\
\text { of the atmosphere }\end{array}$ & {$[0.9,1]$} & Yes \\
\hline 8 & $T_{\mathrm{r} s, \min }$ & ${ }^{\circ} \mathrm{C}$ & Minimum temperature for rain/snow mixture & -1 & No \\
\hline 9 & $T_{\mathrm{rs}, \max }$ & ${ }^{\circ} \mathrm{C}$ & Maximum temperature for rain/snow mixture & +3 & No \\
\hline 10 & $f_{\text {ret }}$ & - & Maximum liquid fraction in snowpack & 0.075 & No \\
\hline 11 & $\rho_{0}$ & $\mathrm{~kg} \mathrm{~m}^{-3}$ & Density of new snow & {$[100,200]$} & Yes \\
\hline 12 & $\eta_{0}$ & $\mathrm{Pas}$ & Compressive viscosity of new snow & $2 \times 10^{11}$ & No \\
\hline 13 & $\rho^{*}$ & $\mathrm{~kg} \mathrm{~m}^{-3}$ & $\begin{array}{l}\text { Characteristic scale for the increase of viscosity with } \\
\text { density: } \eta(\rho)=\eta_{0} e^{\left(\rho-\rho_{0}\right) / \rho^{*}}\end{array}$ & 400 & No \\
\hline 14 & $Z_{\text {act }}$ & $\mathrm{m}$ & Maximum depth of thermally active snow layer & 10 & No \\
\hline 15 & $d_{\text {soil }}$ & $\mathrm{mm}$ & Maximum capacity of soil moisture accounting store & {$[300,500]$} & Yes \\
\hline 16 & $d_{\text {infil }}$ & $\mathrm{mm}$ & Minimum SMA content for infiltration generation & {$\left[0, d_{\text {soil }}\right]$} & Yes \\
\hline 17 & $d_{\text {slow }}$ & $\mathrm{mm}$ & Minimum SMA content for slow surface flow generation & {$\left[d_{\text {infil }}, d_{\text {soil }}\right]$} & Yes \\
\hline 18 & $d_{\text {quick }}$ & $\mathrm{mm}$ & Minimum SMA content for quick surface flow generation & {$\left[d_{\text {slow }}, d_{\text {soil }}\right]$} & Yes \\
\hline 19 & $K_{c}$ & - & Crop coefficient for potential evapotranspiration scaling & 1.0 & No \\
\hline 20 & $f_{\text {imper }}$ & - & Impervious fraction of the subcatchment & 0.0 & No \\
\hline 21 & $\tau_{\text {infil }}$ & days & Characteristic time for infiltration release & & Yes \\
\hline 22 & $\tau_{\text {slow }}$ & days & Characteristic time for slow surface flow release & ] $\left.0, \tau_{\text {infil }}\right]$ & Yes \\
\hline 23 & $\tau_{\text {quick }}$ & days & Characteristic time for quick surface flow release & ] $\left.0, \tau_{\text {slow }}\right]$ & Yes \\
\hline 24 & $d_{\mathrm{gw}}$ & $\mathrm{mm}$ & Maximum capacity of deep storage & {$[300,500]$} & Yes \\
\hline 25 & $d_{\mathrm{gw}, \text { int }}$ & $\mathrm{mm}$ & Deep storage threshold for intermediate flow generation & - & No \\
\hline 26 & $\tau_{\mathrm{gw}}$ & days & Characteristic time for deep storage release & & Yes \\
\hline 27 & $\tau_{\mathrm{gw}, \text { int }}$ & days & Characteristic time for deep storage intermediate release & - & No \\
\hline 28 & C & $\mathrm{ms}^{-1}$ & Celerity for diffusive wave flow routing & & Yes \\
\hline 29 & $D$ & $\mathrm{~m}^{2} \mathrm{~s}^{-1}$ & Diffusivity for diffusive wave flow routing & & Yes \\
\hline
\end{tabular}

where $R_{e}(\varphi, j)$ is extraterrestrial radiation for calendar day $j$ at latitude $\varphi$ and $\sigma=5.6710^{-8} \mathrm{~W} \mathrm{~m}^{-2} \mathrm{~K}^{-4}$ is the Stefan-Boltzmann constant. For the sake of brevity readers are referred to Table 3 for the meaning of other parameters. If the conceptual surface temperature $T_{\text {snow }, s}$ is found greater than $0^{\circ} \mathrm{C}$, it is set to zero in Eq. (15) and the convective flux entering the snowpack is equal to the left-hand side. These assumptions are clearly quite bold, and the resulting model stands at a midpoint between true SEB models and conceptual degree-day models. Such a formulation tries to trade-off between efficiency, parsimony, and spatial transferability.

The soil moisture accounting procedure uses a single storage and three thresholds for generating infiltration and slow and fast runoff components. In this study, we use the potential evapotranspiration formula by Oudin et al. (2005), which is very robust for hydrological modeling.
Finally, the contribution of each subcatchment is routed to the different control nodes using a diffusive wave model with uniform, lumped celerity and diffusivity parameters (see, e.g., Hayami 1951) instead of the original Nash cascade. The same parameter set is used for all subcatchments of the topographic mesh (i.e., only the forcings and the state variables are distributed). Table 3 lists the 29 parameters of the model; 15 of them are calibrated.

\section{b. Inferred parameters}

As mentioned earlier, the main objective of the procedure is to let streamflow measurements help the inference of the drift parameters controlling the precipitation and temperature templates in each weather pattern. Hence, for each trial value of the precipitation increase rate $\alpha_{k}$ (temperature lapse rate $\Gamma_{k}$ ) in WP $k$, we have to perform the variographic analysis of the 
residuals to the drift and of the daily residuals to the template once the latter has been computed (note that with the transformation, the structural function has to be specified for the transformed variable $Y$; see, e.g., Matheron 1974). However, the advantage of working with the decomposition proposed above is that the daily residuals $\lambda\left(\mathbf{x}_{1}, j\right), \ldots, \lambda\left(\mathbf{x}_{n}, j\right)\left[\theta\left(\mathbf{x}_{1}, j\right), \ldots, \theta\left(\mathbf{x}_{n}, j\right)\right]$ to the template at the conditioning locations do not depend on the drift parameters, because by construction the value of the template at those conditioning locations is always the observed value. Consequently, the variography of the daily residuals to the template has to be done only once for each weather pattern.

Finally, we will identify three subsets of parameters:

1) the first subset will be referred to as the precipitation drift parameters: these degrees of freedom are the eight precipitation increase rates $\alpha_{1}, \ldots, \alpha_{8}$ for each weather pattern;

2) the second subset will gather the temperature drift parameters, namely, the eight temperature lapse rates $\Gamma_{1}, \ldots, \Gamma_{8}$; and

3) the last subset consists of the 15 parameters of the hydrological model (including the snow routine).

The whole model (hereafter called hydrometeorological model) thus consists of 31 calibrated parameters.

\section{c. Multiobjective optimization procedure}

As mentioned earlier, the whole hydrometeorological model can produce four types of daily estimates that can be compared with observations, namely, point-scale precipitation estimates, point-scale temperature estimates, point-scale SWE estimates, and catchment-scale streamflow estimates. For a given parameter set (31 parameters), we can thus compute as many goodness-of-fit criteria:

1) If we put a rain gauge aside, we can use it as an ungauged location for independent evaluation of the spatialization scheme (jackknife procedure). We can repeat this procedure for each rain gauge in the network and compute a mean criterion in jackknife validation for the 26 rain gauges $\left\langle C_{P}\right\rangle_{\mathrm{jk}}$ (the brackets and the subscript $\mathrm{jk}$ indicate that we have to run the interpolation 26 times to compute this mean, which is not the case for criteria 3 and 4 below).

2) We can do the same thing for each temperature station and produce a goodness-of-fit criterion for temperature series $\left\langle C_{T}\right\rangle_{\mathrm{jk}}$.

3) The hydrological model transforms the precipitation and temperature fields into discharge time series at one or several subcatchment outlets. Hence, we can compute evaluation criteria for the seven streamflow gauges available and produce a mean criterion $\overline{C_{Q}}$.
4) Similarly, we can run the snow routine at point-scale with the forcings estimated at the locations of the seven cosmic-ray snow sensors, in order to compare the simulations with observed SWE time series. Hence, we can produce a mean criterion $\overline{C_{\mathrm{SWE}}}$.

For all variables, the criterion used is the Kling-Gupta efficiency (KGE; see Gupta et al. 2009), which reads

$C_{X}=1-\sqrt{\left(\frac{\mu_{\hat{X}}}{\mu_{X}}-1\right)^{2}+\left(\frac{\sigma_{\hat{X}}}{\sigma_{X}}-1\right)^{2}+(r-1)^{2}}$,

where $\mu_{X}$ and $\sigma_{X}$ are the mean and standard deviation of the time series of the observed variable $X, \mu_{\hat{X}}$ and $\sigma_{\hat{X}}$ are the mean and standard deviation of simulated variable $\hat{X}$, and

$$
r=\frac{\operatorname{Cov}(X, \hat{X})}{\sigma_{X} \sigma_{\hat{X}}}
$$

is the Pearson correlation coefficient between $X$ and $\hat{X}$. The KGE has three components: a penalty on bias (simulated-to-observed mean, i.e., the first moment of the distribution of the variable $X$ ), a penalty on the ratio of simulated-to-observed standard deviation (second moment), and a penalty on correlation (i.e., on timing errors). A perfect simulation would have all penalties equal to zero under the square root in Eq. (16), hence a KGE equal to 1 . Then, $\overline{C_{X}}$ is simply the mean value for all sites where a time series of variable $X$ is available:

$$
\overline{C_{X}}=\frac{1}{n_{\text {sites }}} \sum_{i=1}^{n_{\text {sites }}} C_{X_{i}} .
$$

The first two criteria on rainfall and temperature are solely dependent on the drift parameter subsets (moreover, the search for the optimal parameter subset with respect to these criteria can be split into eight singleparameter searches). However, the third and fourth criteria are sensitive to all three subsets since the quality of the discharge and SWE simulations produced by the hydrological model relies not only on its own parameters, but also on the quality of the estimated forcing fields. For these reasons, we can perform a multiobjective calibration of the whole parameter set using a multiobjective evolutionary (i.e., trial and error) algorithm, namely, the CaRaMEL algorithm (Calage Rapide par Algorithme Multi-Objectif Evolutionnaire; see, e.g., Le Moine 2009; Rothfuss et al. 2012; Magand et al. 2014).

In practice, since temperature is much easier to interpolate than precipitation, we perform a threeobjective optimization using criteria $\left\langle C_{P}\right\rangle_{\mathrm{jk}}$ on precipitation, $\overline{C_{Q}}$ on discharge time series, and $\overline{C_{\mathrm{SWE}}}$ on 
snow water equivalent time series. The algorithm starts with a randomly generated "population" of parameter sets. For each trial parameter set ("individual" in the population), we run the whole hydrometeorological model and we compute the three criteria. Then, on the basis of the previously tested parameter sets, the algorithm proposes new trial parameter sets (new "generation") in order to identify the Pareto solutions to the multiobjective problem.

\section{d. Implementation}

For a given parameter set (i.e., 31 parameters), generating the gridded forcings at the resolution of $1 \mathrm{~km}^{2}$ over the whole catchment $\left(3600 \mathrm{~km}^{2}\right.$, hence 3600 grid points) is the most computationally demanding task. All models (interpolation schemes and hydrological model) are run in a Scilab environment with calls to subroutines written in $\mathrm{C}$ and FORTRAN. Multiple right-hand-side kriging systems are solved using LAPACK subroutines (symmetric positive definite solver using Cholesky factorization for simple kriging and general symmetric solver using Bunch-Kaufman lower/upper/permutation factorization for ordinary kriging; see Anderson et al. 1999). Since the kriging weights solely depend on the kriging configuration and not on the daily values at the conditioning points, the factorization and the computation of the weights have to be done only once for each weather pattern, no matter the length of the period to be simulated. As a result, one run of the whole direct model (generation of forcing fields + semidistributed hydrological simulation) takes $5-10 \mathrm{~s}$ to complete for a $20-\mathrm{yr}$ period on a typical desktop machine. This is reasonably fast enough for use with an MOEA that converges in a few thousand evaluations of the direct problem.

\section{Results}

The two approaches (independent analysis versus joint calibration) are evaluated using a classical splitsample test technique (Klemeš 1986). The complete period 1981-2004 is divided into two subperiods: the first period starts on 1 August 1981 and ends on 31 July 1993, and the second period starts on 1 August 1992 and ends on 31 July 2004. A 1-yr warm-up period is used each time, so that the criteria are calculated on strictly nonoverlapping periods, from 1 August 1982 to 31 July 1993 and from 1 August 1993 to 31 July 2004, respectively, in order to maximize the use of available data.

Also, in order to make a full use of all available data, we perform a symmetrical split-sample test: the first cross-validation test is done by calibrating the model in the first period 1982-93 (i.e., identifying the Pareto solutions) and then evaluating the solutions in the
TABLE 4. Drift parameters (precipitation increase rates) in each weather pattern obtained in the independent analysis.

\begin{tabular}{|c|c|c|}
\hline & $\begin{array}{c}\text { Calibration } \\
1982-93\end{array}$ & $\begin{array}{c}\text { Calibration } \\
1993-2004\end{array}$ \\
\hline$\alpha_{1}$ increase rate in WP 1 & $0.10 \% \mathrm{hm}^{-1}$ & $1.55 \% \mathrm{hm}^{-1}$ \\
\hline$\alpha_{2}$ increase rate in WP 2 & $2.64 \% \mathrm{hm}^{-1}$ & $4.95 \% \mathrm{hm}^{-1}$ \\
\hline$\alpha_{3}$ increase rate in WP 3 & $3.48 \% \mathrm{hm}^{-1}$ & $7.95 \% \mathrm{hm}^{-1}$ \\
\hline$\alpha_{4}$ increase rate in WP 4 & $1.82 \% \mathrm{hm}^{-1}$ & $4.37 \% \mathrm{hm}^{-1}$ \\
\hline$\alpha_{5}$ increase rate in WP 5 & $4.35 \% \mathrm{hm}^{-1}$ & $3.47 \% \mathrm{hm}^{-1}$ \\
\hline$\alpha_{6}$ increase rate in WP 6 & $1.26 \% \mathrm{hm}^{-1}$ & $0.10 \% \mathrm{hm}^{-1}$ \\
\hline$\alpha_{7}$ increase rate in WP 7 & $3.32 \% \mathrm{hm}^{-1}$ & $2.06 \% \mathrm{hm}^{-1}$ \\
\hline$\alpha_{8}$ increase rate in WP 8 & $4.57 \% \mathrm{hm}^{-1}$ & $1.95 \% \mathrm{hm}^{-1}$ \\
\hline $\begin{array}{l}\left\langle C_{P}\right\rangle_{\mathrm{jk}} \text { mean } \mathrm{KGE} \text { in jackknife } \\
\text { validation at the } 26 \text { rain gauges, } \\
\text { in the calibration period }\end{array}$ & 0.769 & 0.776 \\
\hline $\begin{array}{l}\text { Mean KGE }\left\langle C_{P}\right\rangle_{\mathrm{jk}} \text { in jackknife } \\
\text { validation at the } 26 \text { rain gauges, } \\
\text { in the other (validation) period }\end{array}$ & 0.771 & 0.764 \\
\hline
\end{tabular}

validation period 1993-2004. Then we switch the roles of the two periods: we build the Pareto front in the second period 1993-2004, and then we evaluate the solutions with period 1 (1982-93) as the control period.

\section{a. Independent analysis experiment}

The independent analysis consists of first calibrating the increase rate parameters $\alpha_{1}, \ldots \alpha_{8}$ against rainfall gauges data only, and then calibrating the parameters of the hydrological with these fixed parameters. The $\alpha_{k}$ values are calibrated so as to maximize the mean KGE $\left\langle C_{P}\right\rangle_{\mathrm{jk}}$ in jackknife validation for the 26 gauges: the values obtained in the two periods are displayed in Table 4.

Then, the hydrological model is calibrated using the multiobjective algorithm with two objective functions: the mean KGE $\overline{C_{Q}}$ at the seven streamflow gauges and the mean $\mathrm{KGE} \overline{C_{\mathrm{SWE}}}$ at the seven cosmic-ray snow sensors. Figure 10 presents the Pareto fronts obtained in calibration.

\section{b. Joint calibration experiment}

As stated in the description of the HAI procedure, we performed the joint calibration of the drift parameters and the parameters of the hydrological model. The threeobjective Pareto fronts obtained in each period are displayed in Fig. 11.

The concept of Pareto optimality is intrinsically linked to the notion of trade-off between different requirements, which is exactly what the HAI procedure aims at. For this reason, we will focus on two subsets of solutions extracted from the Pareto fronts of Fig. 11:

- The subset displayed in blue represents all the tradeoff solutions between $\overline{C_{Q}}$ and $\overline{C_{\mathrm{SWE}}}$, with the constraint that $\left\langle C_{P}\right\rangle_{\mathrm{jk}}$ is maximum. This subset is precisely 

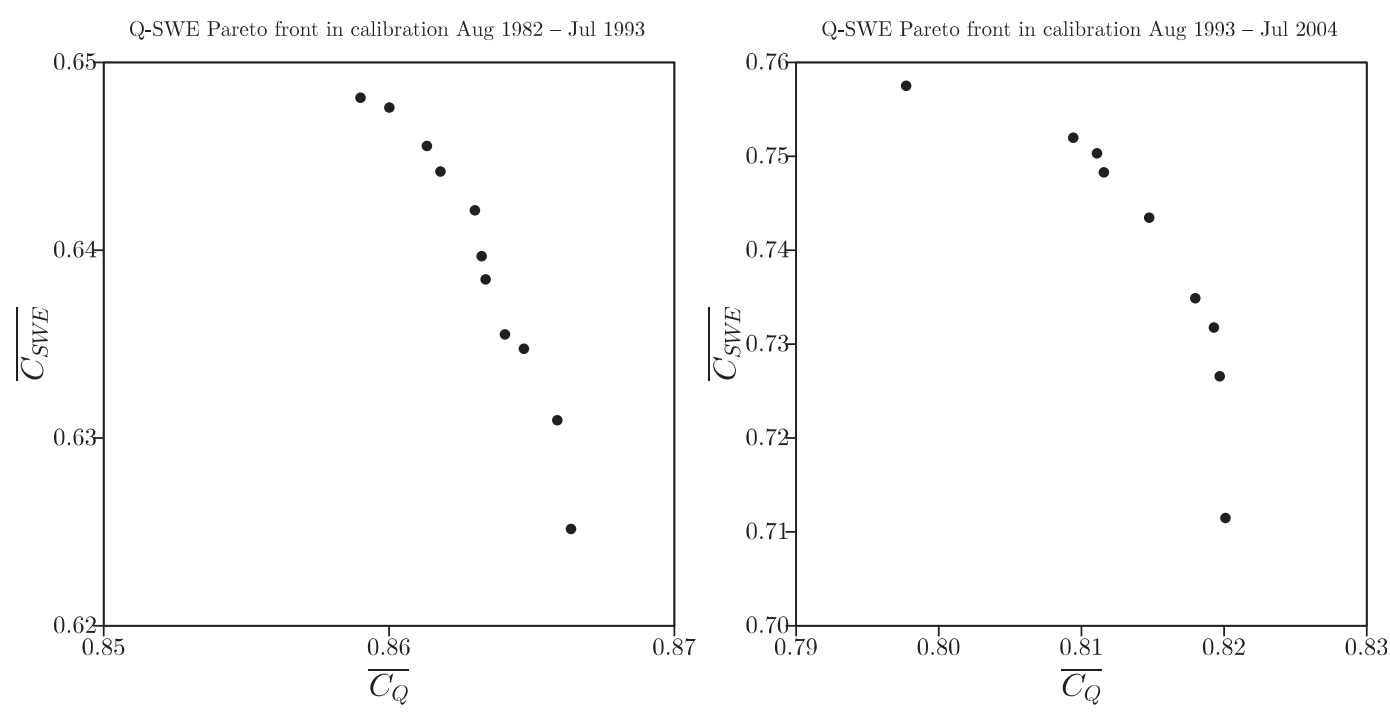

FIG. 10. Two-objective Pareto fronts obtained during calibration of the parameters of the hydrological model in (left) period 1 (1982-93) and (right) period 2 (1993-2004). In each period, the drift parameters $\overline{C_{\mathrm{SwE}}}$ and $\overline{C_{Q}}$ are fixed to their values obtained through independent analysis.

the same as the 2D Pareto front obtained in the second step of the independent analysis (Fig. 10).

- The subset highlighted in red is the solutions that maximize a weighted mean of the three criteria, with the weights set to the inverse of the standard deviation of each criteria in the full Pareto front (so as to eliminate the effect that each criterion spans a different range). We selected 30 solutions in order to be able to produce distributions of the parameters in this set.

\section{c. Posterior distribution of drift parameters in the joint calibration versus independent analysis}

In Fig. 12 we show the empirical PDFs for the precipitation increase rates in the eight weather patterns, for each approach (independent analysis and joint calibration) and each period (1982-93 and 1993-2004). A perfectly formulated and perfectly identifiable interpolation model would yield identical drift parameters in these two periods. These plots show that most of the time, the distributions obtained in the two periods are closer to each other with the joint calibration (solid black and gray histograms) than with the independent analysis (vertical dotted bars, black and gray). The overlap is especially improved for weather patterns that occur frequently and/or have strong gradients, such as WP 2: in both periods, the PDF of parameter $\alpha_{2}$ is centered around $5 \%-6 \% \mathrm{hm}^{-1}$, while the mismatch is important with the independent analysis $(2.64 \%$ versus $4.95 \% \mathrm{hm}^{-1}$ ). An improvement is also observed for $\alpha_{3}$, $\alpha_{4}$, and $\alpha_{7}$, which all bring significant amounts of precipitation (see Table 2). Conversely, parameter $\alpha_{5}$ (WP 5) seems better identified in the independent analysis than in the joint calibration: this is a consequence of its rare occurrence and low hydrological importance $\left(5.9 \%\right.$ of all days and only $39 \mathrm{~mm} \mathrm{yr}^{-1}$ on average; see Table 2 again).

Interestingly (and reassuringly), the weather pattern associated with the fastest circulation (WP 2, Steady oceanic) has the highest calibrated increase rate, in accordance with Eq. (2).

\section{d. Robustness of parameter identification}

To assess the robustness of both approaches (independent versus joint calibration), we have to evaluate them in a period different from the one used for calibration (Andréassian et al. 2009). This is the reason why we performed a symmetric split sample test (Klemeš 1986). The results are shown in Fig. 13: for each criterion (on jackknife $P$ gauges, on SWE, and on streamflow $Q$ ) and each period (from August 1982 to July 1993 and from August 1993 to July 2004), we plot four box plots:

1) the distribution of the criterion on the period, given by the subset of parameterizations obtained with the independent analysis in the same period;

2) the distribution of the criterion on the period, given by the subset of parameterizations obtained with the joint calibration in the same period;

3) the distribution of the criterion on the period, given by the subset of parameterizations obtained with the independent analysis on the other period (temporal cross validation of the independent analysis); and 


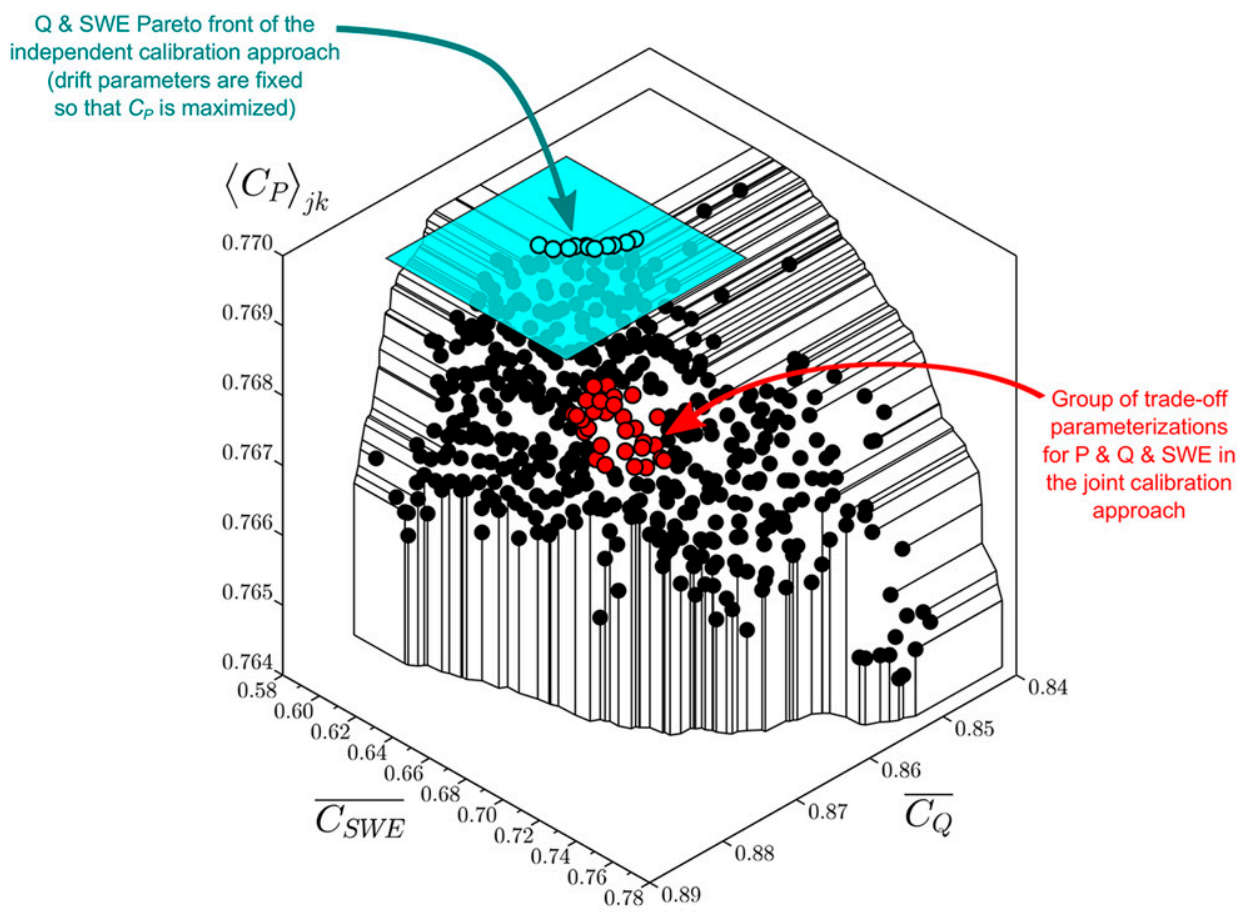

Pareto front in calibration Aug 1982 - Jul 1993

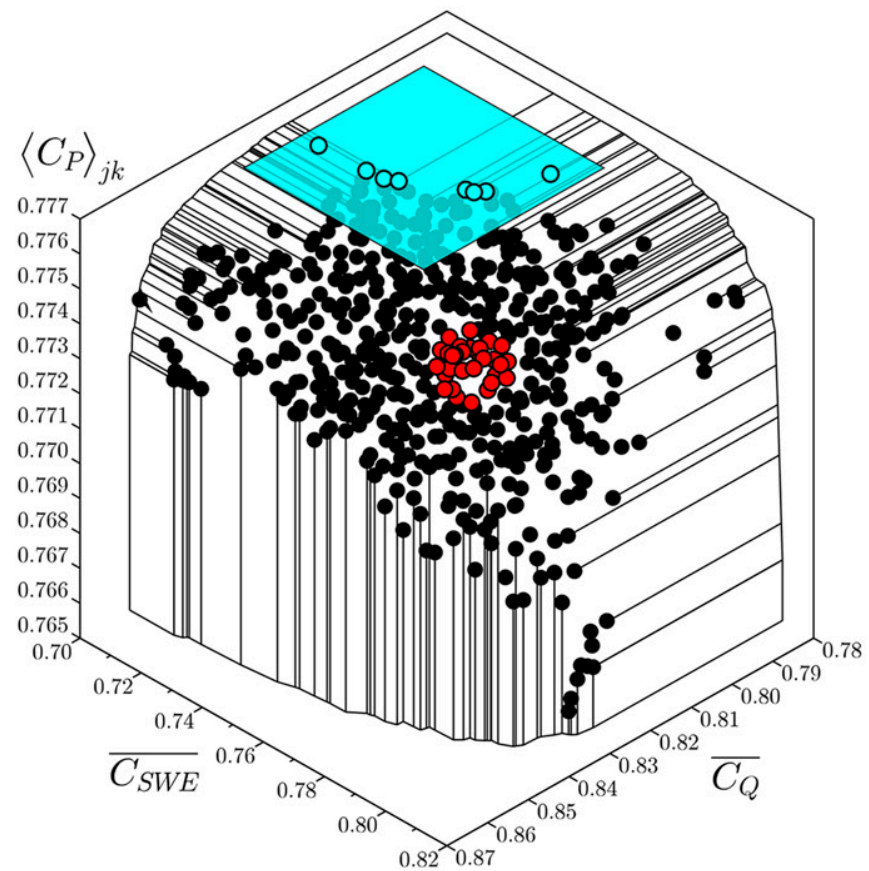

Pareto front in calibration Aug 1993 - Jul 2004

FIG. 11. Three-objective Pareto fronts obtained during calibration in (top) period 1 (1982-93) and (bottom) period 2 (1993-2004). Each dot is a simulation (i.e., a parameter set) for which three criteria are computed: $\overline{C_{Q}}$ is the mean KGE on the seven streamflow gauges, $\overline{C_{\mathrm{SWE}}}$ is the mean KGE on the seven point-scale SWE measurements, and $\left\langle C_{P}\right\rangle_{\mathrm{jk}}$ is the mean KGE in jackknife validation at the 26 rain gauges (26 jackknife tests for each parameter set). 
Weather Pattern 1 (frequency: $7.6 \%$ )

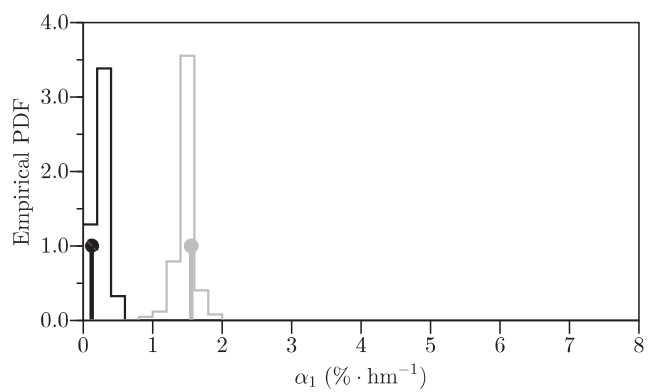

Weather Pattern 3 (frequency: 7.8\%)

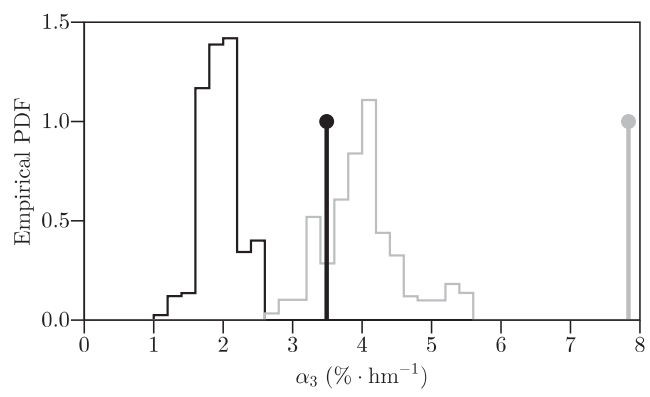

Weather Pattern 5 (frequency: 5.9\%)

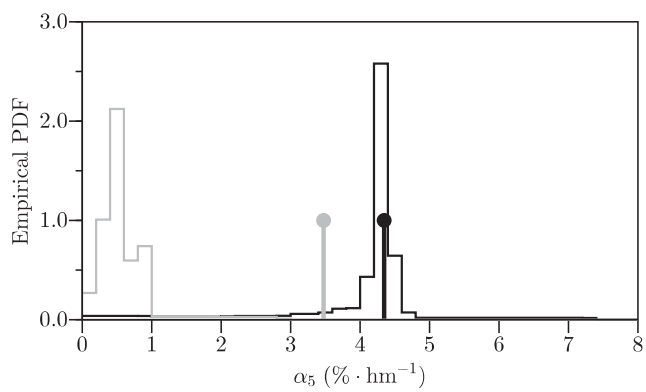

Weather Pattern 7 (frequency: $3.6 \%$ )

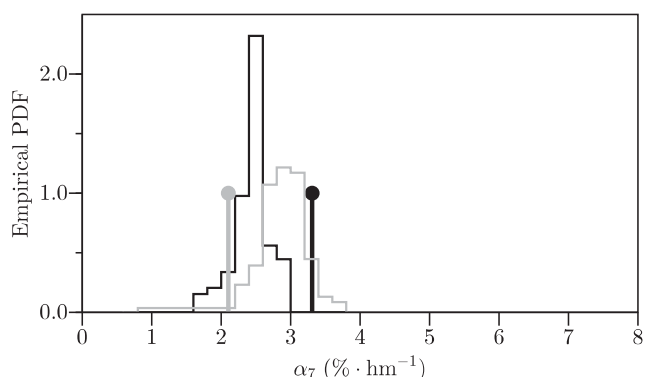

Weather Pattern 2 (frequency: 23.8\%)

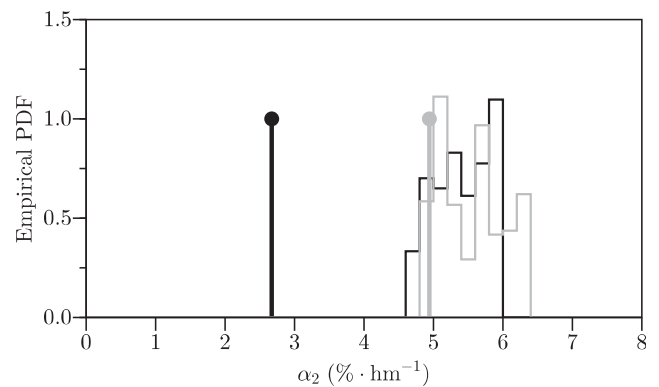

Weather Pattern 4 (frequency: 18.4\%)

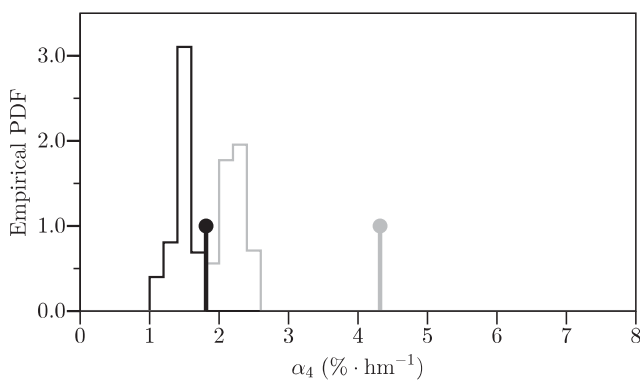

Weather Pattern 6 (frequency: 5.6\%)

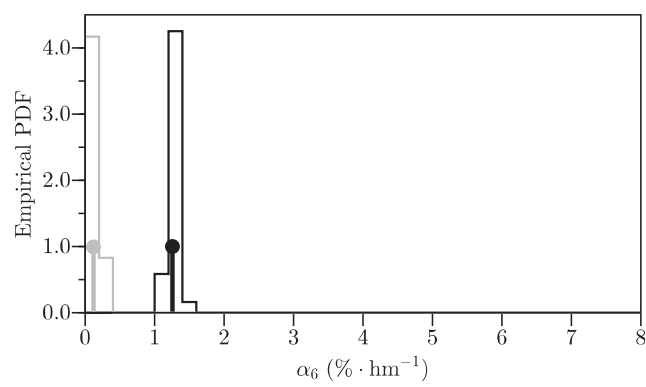

Weather Pattern 8 (frequency: 27.3\%)

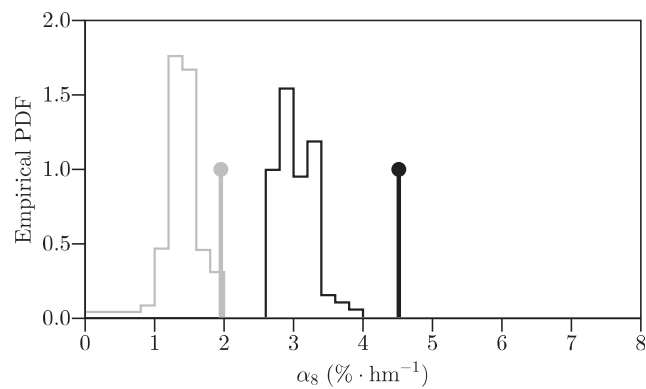

FIG. 12. Empirical densities for the precipitation increase rates in the eight weather patterns: (top left) WP 1 to (bottom right) WP 8. Solid black lines indicate the PDFs in joint calibration in the period 1982-93; solid gray lines indicate the PDFs in the period 1993-2004. Thick vertical bars with a dot at the top indicate the values of the same rates obtained through independent analysis in each period (these are Dirac distributions), with the same color code. 
$\overline{C_{Q}}$ in period $1982-1993$

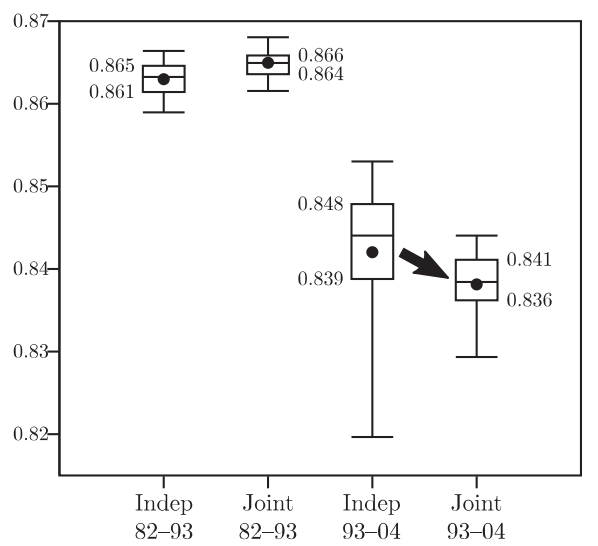

$\overline{C_{S W E}}$ in period $1982-1993$

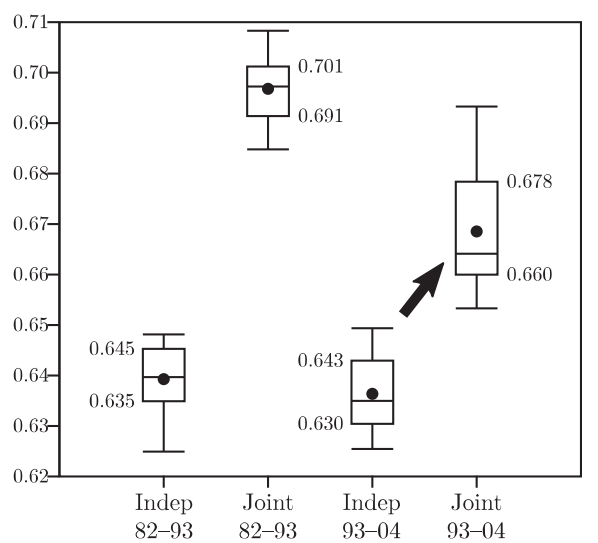

$\left\langle C_{P}\right\rangle_{j k}$ in period $1982-1993$

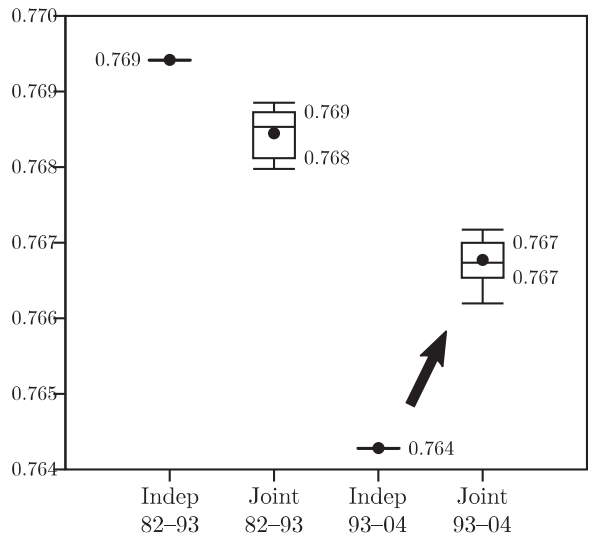

$\overline{C_{Q}}$ in period $1993-2004$

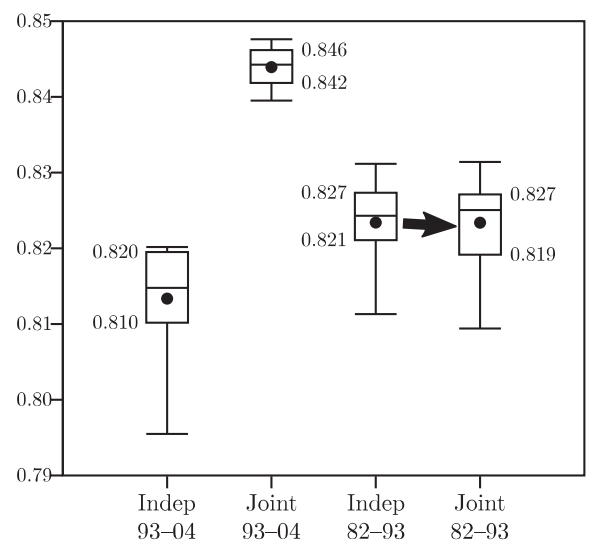

$\overline{C_{S W E}}$ in period $1993-2004$

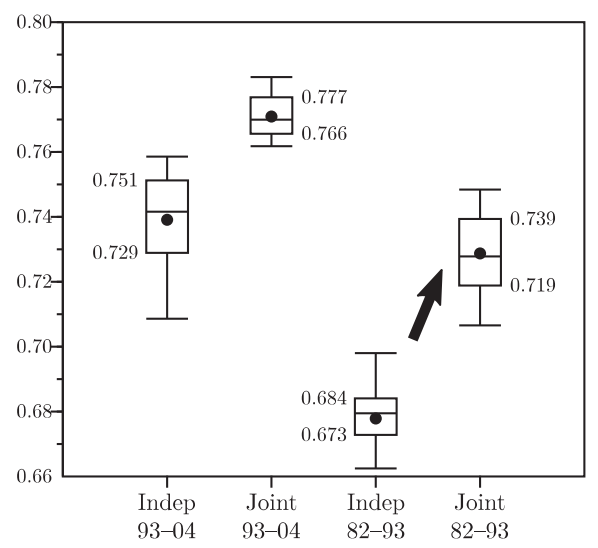

$\left\langle C_{P}\right\rangle_{j k}$ in period 1993-2004

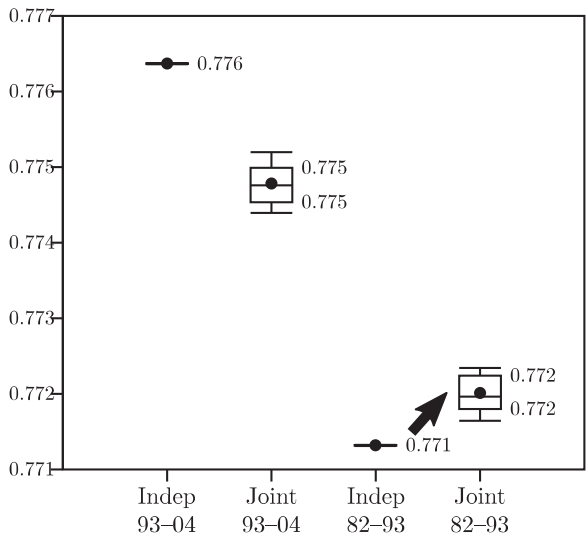

FIG. 13. Temporal cross-validation results. For each criterion-(top) $\overline{C_{Q}}$ on streamflow times series, (middle) $\overline{C_{\mathrm{SWE}}}$ on cosmic-ray snow sensors, and (bottom) $\left\langle C_{P}\right\rangle_{\mathrm{jk}}$ on jackknife rain gauges-and for each period-(left) from August 1982 to July 1993 and (right) from August 1993 to July 2004 - we show four box plots. The distribution of the criterion on the period given by 1 ) the subset of parameterizations obtained with the independent analysis in the same period, 2) the subset of parameterizations obtained with the joint calibration in the same period, 3) the subset of parameterizations obtained with the independent analysis in the other period, and 4) the subset of parameterizations obtained with the joint calibration in the other period. The bottom and top of each box are the first and third quartiles (figures are displayed); the line inside the box is the median, and the ends of the whiskers are the 5th and 95th percentiles. Arrows indicate how the cross-validation distributions (which are the true measures of model performance) change when we use the HAI approach instead of the independent analysis. 

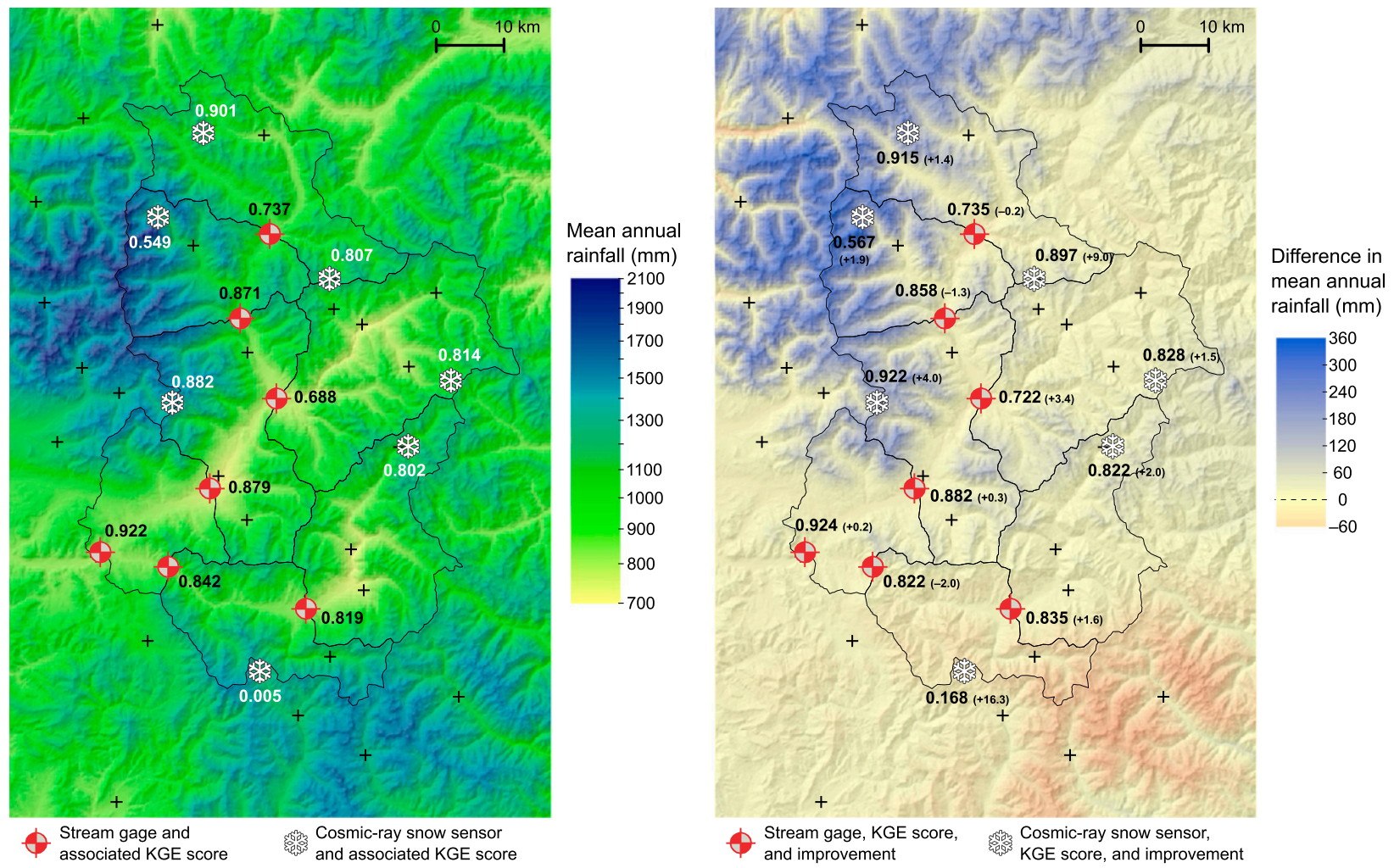

FIG. 14. (left) Map of a reference control simulation in the period 1993-2004 using the parameters obtained in the period 1982-93 with the independent analysis. (right) Differences with the corresponding control runoff of the joint calibration. Red and gray circles indicate the precipitation gauges with their associated KGE scores and white snowflakes, the SWE gauges and scores.

4) the distribution of the criterion on the period, given by the subset of parameterizations obtained with the joint calibration on the other period (temporal cross validation of the joint calibration).

The first two plots (top left and top right) show that the joint calibration outperforms the independent analysis during calibration (as anticipated, since more parameters are calibrated at once). In cross-validation tests, it yields a small loss in streamflow simulation compared with the independent analysis for one cross validation (calibration on 1993-2004 and validation on 1982-93), and almost no difference in the symmetric validation (calibration on 1982-93 and validation on 1993-2004). This means that, from the sole point of view of streamflow simulation, the joint calibration is not superior to the independent analysis: even if the precipitation and temperature drift parameters are biased in the first step of the independent analysis, the second step (the calibration of the hydrological model) can compensate for biases in a way that is still robust (i.e., in a way that can be transferred successfully in validation).

The results for SWE simulation have a much clearer trend. Again, as anticipated, the joint calibration outperforms the independent analysis in calibration. However, for this variable the improvement is very well transferred in validation (for both cross validations from 1982-93 to 1993-2004 and from 1993-2004 to 1982-93). This means that the joint calibration yields much more robust point-scale precipitation and temperature estimates at high elevation than the independent analysis. This result confirms the previous observations about the distributions of the drift parameters in both periods, which seemed closer to each other with the joint calibration than with the independent analysis.

Surprisingly enough, the same results are found for the last criterion $\left\langle C_{P}\right\rangle_{\mathrm{jk}}$. Note that in this case, the cross validation is both temporal and spatial: for example, we try to simulate the daily precipitation at one of the 26 gauges during the period 1993-2004, using the remaining 25 gauges and a parameter set $\left(\alpha_{1}, \ldots, \alpha_{8}\right)$ calibrated in the period 1982-93. This time, we verify that the independent analysis gives better results in calibration (by definition, we first maximize this criterion $\left\langle C_{P}\right\rangle_{\mathrm{jk}}$, and then calibrate the hydrological model). However, the joint calibration, which is only suboptimal on $\left\langle C_{P}\right\rangle_{\mathrm{jk}}$ by construction, yields better results in temporal cross validation. 


\section{e. Summary of the differences}

The maps in Fig. 14 summarize the changes in different variables simulated in the catchment and are a mere illustration of the results shown in Fig. 13. The left map is a reference control simulation in the period 1993-2004, that is, the mean annual precipitation map produced with the drift parameters $\alpha_{1}, \ldots, \alpha_{8}$ obtained in the independent analysis in the period 1982 93, and the associated KGE scores at streamflow gauges and SWE sensors. The right map is the corresponding control run of the joint calibration; it shows the difference in mean annual precipitation and the differences in the KGE scores. The joint calibration yields higher annual precipitation on average at the catchment scale and also a different seasonal repartition (seasonal maps are not shown for the sake of brevity). Increases are seen in a much greater area than decreases, and adjustments are much greater when increased than decreased.

\section{Conclusions}

Because of the scarcity and lack of spatial representativeness of point-scale temperature and precipitation observations in mountain areas, an interpolation step of these key forcing variables is required before any hydrological modeling exercise. The quality of hydrological simulations strongly depends on the quality of these forcings. From the point of view of processes, meteorology comes first, and hydrology comes second.

In this study, we tried to show that, from an information point of view, the estimation of meteorological variables (e.g., precipitation and temperature) may actually benefit from hydrological measurements. We presented a proof-of-concept that a joint calibration of the drift parameters (precipitation increase rates and temperature lapse rates) and of the hydrological model's parameters was possible and, in fact, desirable. Cross-validation results show that, in a multiobjective framework, point-scale measurements can help inform the model about mesoscale dynamics and vice versa.

For this, we developed an interpolation scheme of daily precipitation and temperature fields allowing for a correct reproduction of spatial and temporal statistics at various scales-support sizes (from event scale to annual, and from point scale to catchment scale) with, for example, full consideration of mean-variance relationships and spatial intermittence in precipitation, in addition to the more classical parameterization of orographic effects using increase or lapse rate parameters (drift parameters). The main originality of this study is the joint calibration of these drift parameters together with the parameters of a semidistributed, daily time step hydrological model.

The HAI procedure seems to demonstrate that it is preferable to solve a single, loosely constrained problem (the joint calibration) rather than to solve a first, very poorly constrained problem (the interpolation of forcings based on gauge data only) and a second, artificially overconstrained problem (the calibration of the hydrological model with prescribed forcings). Drift parameters are better identified in the HAI approach, and the identifiability is especially improved for the weather patterns that bring a lot of precipitation on average.

Our current work focuses on using other hydrological observations for the joint calibration, such as satellitederived areal snow cover fraction (SCF): this variable is already widely used to calibrate the parameters of hydrological models (e.g., Andreadis and Lettenmaier 2006; Duethmann et al. 2014). Another response variable could be glacier extent, a variable that is used by, for example, Immerzeel et al. (2012) in order to infer catchment-scale annual precipitation from glacier mass balance.

The methodology presented in the paper will also be extended to other forcing variables, such as incoming shortwave and longwave radiation and relative humidity, in order to further improve the simulation of pointscale snow water equivalent with the same domainwide parameterization of the snow model. For this task, new predictors such as aspect, slope, or windward or leeward indices will be tested in order to improve the geostatistical model.

Acknowledgments. Financial support for this study was provided by the EC2CO Programme from the French National Institute of Sciences of the Universe (CNRS/INSU). We thank the two anonymous reviewers for providing very helpful, detailed, and constructive comments throughout the review process.

\section{APPENDIX}

\section{Gaussian Transformation of the Local Scaling Factor}

a. Gibbs sampling at nonrainy gauges

1) At the locations $\mathbf{x}^{n, z}$ where the rainfall (and hence the local scaling ratio) is nonzero, we set $y\left(\mathbf{x}^{n, z}\right)=$ $\mathscr{N}_{0,1}^{-1}\left\{F_{\Lambda}\left[\lambda\left(\mathbf{x}^{n, z}\right)\right]\right\}$. At the locations $\mathbf{x}^{z}$ where the rainfall is zero, we initialize $y\left(\mathbf{x}^{z}\right)=$ $\mathscr{N}_{0,1}^{-1}\left(f_{0}\right)=S_{y}$. 
2) We randomly select a location $\mathbf{x}^{z}$ with zero rainfall. The distribution of the selected value is estimated conditionally to all the other values by ordinary kriging (a linear variogram being the best structural function): its density is a Gaussian PDF $p$ with mean $\mu_{\mathrm{SK}}$ and variance $\sigma_{\mathrm{SK}}^{2}$.

3) Since we picked a zero-rainfall location, we know that $y\left(\mathbf{x}^{z}\right)<S_{y}$. To accelerate convergence, we thus compute the conditional expectation

$$
\mathbb{E}\left[Y\left(\mathbf{x}^{z}\right) \mid Y\left(\mathbf{x}^{z}\right)<S_{y}\right]=\frac{1}{\int_{-\infty}^{S_{y}} p(y) d y} \int_{-\infty}^{S_{y}} y p(y) d y,
$$

which, under the Gaussian assumption, admits the closed form

$$
\begin{aligned}
& \mathbb{E} {\left[Y\left(\mathbf{x}^{z}\right) \mid Y\left(\mathbf{x}^{z}\right)<S_{y}\right] } \\
&=\mu_{\mathrm{SK}}-\sqrt{\frac{2}{\pi}} \sigma_{\mathrm{SK}} \frac{e^{-\left[\left(S_{y}-\mu_{\mathrm{SK}}\right)^{2} / 2 \sigma_{\mathrm{SK}}^{2}\right]}}{1+\operatorname{erf}\left(\frac{S_{y}-\mu_{\mathrm{SK}}}{\sigma_{\mathrm{SK}} \sqrt{2}}\right)} .
\end{aligned}
$$

4) We replace the old value $y\left(\mathbf{x}^{z}\right)$ at the selected location with this estimation, and loop back to step 2 until the norm of the vector of estimates at the $n$ locations changes by less than a given error criterion.

\section{b. Reverse transformation}

Given the expressions

$$
\left\{\begin{array}{l}
F_{\Lambda}(\lambda)=f_{0}+\frac{1-f_{0}}{2}\left[1+\operatorname{erf}\left(\frac{\ln \lambda-\mu}{\sigma \sqrt{2}}\right)\right] \\
\left(F_{\Lambda}^{-1} \circ N\right)(y)=\phi^{-1}(y)=\exp \left\{\mu+\sigma \sqrt{2} \operatorname{erf}^{-1}\left[\frac{\operatorname{erf}(y / \sqrt{2})-f_{0}}{1-f_{0}}\right]\right\}
\end{array}\right.
$$

it is clear that there is no closed form for the expectation of the local scaling factor (mean of the black PDF in Fig. 9):

$$
\begin{aligned}
\tilde{\lambda}\left(\mathbf{x}_{0}\right) & =\mathbb{E}\left[\Lambda\left(\mathbf{x}_{0}\right) \mid \lambda\left(\mathbf{x}_{1}\right), \ldots, \lambda\left(\mathbf{x}_{n}\right)\right] \\
& =\mathbb{E}\left\{\phi^{-1}\left[Y\left(\mathbf{x}_{0}\right)\right] y\left(\mathbf{x}_{1}\right), \ldots, y\left(\mathbf{x}_{n}\right)\right\} \\
& =\int_{-\infty}^{+\infty} \phi^{-1}(y) \frac{1}{\sigma_{\mathrm{SK}} \sqrt{2 \pi}} e^{-\left[\left(y-\mu_{\mathrm{SK}}\right)^{2} / 2 \sigma_{\mathrm{SK}}^{2}\right]} d y \\
& =\frac{1}{\sqrt{\pi}} \int_{-\infty}^{+\infty} \phi^{-1}\left(\mu_{\mathrm{SK}}+\sqrt{2} \sigma_{\mathrm{SK}} u\right) e^{-u^{2}} d u .
\end{aligned}
$$

However, the latter integral can be efficiently evaluated using Gauss-Hermite quadrature:

$$
\begin{array}{r}
\int_{-\infty}^{+\infty} \phi^{-1}\left(\mu_{\mathrm{SK}}+\sqrt{2} \sigma_{\mathrm{SK}} u\right) e^{-u^{2}} d u \\
\approx \sum_{i=1}^{m} w_{i} \phi^{-1}\left(\mu_{\mathrm{SK}}+\sqrt{2} \sigma_{\mathrm{SK}} u_{i}\right),
\end{array}
$$

where $u_{i}$ and $w_{i}$ are the abscissas and weights, respectively, of the $m$-point quadrature [see, e.g., Press et al. (1992) for implementation].

\section{REFERENCES}

Alter, J. C., 1919: Normal precipitation in Utah. Mon. Wea. Rev., 47, 633-636, doi:10.1175/1520-0493(1919)47<633: NPIU $>2.0 . \mathrm{CO} ; 2$.

Anderson, E., and Coauthors, 1999: LAPACK Users' Guide. 3rd ed. Society for Industrial and Applied Mathematics, 429 pp.
Andreadis, K. M., and D. P. Lettenmaier, 2006: Assimilating remotely sensed snow observations into a macroscale hydrology model. Adv. Water Resources, 29, 872-886, doi:10.1016/ j.advwatres.2005.08.004.

Andréassian, V., and Coauthors, 2009: Crash tests for a standardized evaluation of hydrological models. Hydrol. Earth Syst. Sci., 13, 1757-1764, doi:10.5194/hess-13-1757-2009.

Barrows, H. K., 1933: Precipitation and runoff and altitude relations for Connecticut River. Trans. Amer. Geophys. Union, 14, 396-406, doi:10.1029/TR014i001p00396.

Bastola, S., and V. Misra, 2014: Evaluation of dynamically downscaled reanalysis precipitation data for hydrological application. Hydrol. Processes, 28, 1989-2002, doi:10.1002/hyp.9734.

Bourqui, M., F. Hendrickx, and N. Le Moine, 2011: Long-term forecasting of flow and water temperature for cooling systems: Case study of the Rhone River, France. IAHS Publ., 348, $135-142$.

Brown, D. P., and A. C. Comrie, 2002: Spatial modeling of winter temperature and precipitation in Arizona and New Mexico, USA. Climate Res., 22, 115-128, doi:10.3354/cr022115.

Charbonneau, R., J.-P. Fortin, and G. Morin, 1977: The CEQUEAU model: Description and examples of its use in problems related to water resource management. Hydrol. Sci. Bull., 22, 193-202, doi:10.1080/02626667709491704.

Clark, M. P., and Coauthors, 2011: Representing spatial variability of snow water equivalent in hydrologic and land-surface models: A review. Water Resour. Res., 47, W07539, doi:10.1029/ 2011WR010745.

Dai, A., I. Y. Fung, and A. D. Del Genio, 1997: Surface observed global land precipitation variations during 1900-88. J. Climate, 10, 2943-2962, doi:10.1175/1520-0442(1997)010<2943: SOGLPV $>2.0 . \mathrm{CO} ; 2$.

Daly, C., 2006: Guidelines for assessing the suitability of spatial climate data sets. Int. J. Climatol., 26, 707-721, doi:10.1002/ joc. 1322 . 
_ , R. P. Neilson, and D. L. Phillips, 1994: A statisticaltopographic model for mapping climatological precipitation over mountainous terrain. J. Appl. Meteor., 33, 140-158, doi:10.1175/1520-0450(1994)033<0140:ASTMFM>2.0.CO;2.

_ W. P. Gibson, G. H. Taylor, G. L. Johnson, and P. Pasteris, 2002: A knowledge-based approach to the statistical mapping of climate. Climate Res., 22, 99-113, doi:10.3354/cr022099.

_, E. H. Helmer, and M. Quinones, 2003: Mapping the climate of Puerto Rico, Vieques, and Culebra. Int. J. Climatol., 23, 1359-1381, doi:10.1002/joc.937.

_, M. Halbleib, J. I. Smith, W. P. Gibson, M. K. Doggett, G. H. Taylor, J. Curtis, and P. P. Pasteris, 2008: Physiographically sensitive mapping of climatological temperature and precipitation across the conterminous United States. Int J. Climatol., 28, 2031-2064, doi:10.1002/joc.1688.

Dettinger, M., 2014: Impacts in the third dimension. Nat. Geosci., 7, 166-167, doi:10.1038/ngeo2096.

Duethmann, D., J. Zimmer, A. Gafurov, A. Güntner, D. Kriegel, B. Merz, and S. Vorogushyn, 2013: Evaluation of areal precipitation estimates based on downscaled reanalysis and station data by hydrological modelling. Hydrol. Earth Syst. Sci., 17, 2415-2434, doi:10.5194/hess-17-2415-2013.

— J. Jeters, T. Blume, S. Vorogushyn, and A. Güntner, 2014: The value of satellite-derived snow cover images for calibrating a hydrological model in snow-dominated catchments in Central Asia. Water Resour. Res., 50, 2002-2021, doi:10.1002/2013WR014382.

Funk, C., J. Michaelsen, J. Verdin, G. Artan, G. Husak, G. Senay, H. Gadain, and T. Magadazire, 2003: The collaborative historical African rainfall model: Description and evaluation. Int J. Climatol., 23, 47-66, doi:10.1002/joc.866.

Garavaglia, F., J. Gailhard, E. Paquet, M. Lang, R. Garçon, and P. Bernardara, 2010: Introducing a rainfall compound distribution model based on weather patterns sub-sampling. Hydrol. Earth Syst. Sci., 14, 951-964, doi:10.5194/hess-14-951-2010.

Goovaerts, P., 2000: Geostatistical approaches for incorporating elevation into spatial interpolation of rainfall. J. Hydrol., 228, 113-129, doi:10.1016/S0022-1694(00)00144-X.

Gottardi, F., 2009: Estimation statistique et réanalyse des précipitations en montagne: Utilisation d'ébauches par types de temps et assimilation de données d'enneigement. Application aux grands massifs montagneux français. Ph.D. thesis, Grenoble INP/EDF, $284 \mathrm{pp}$.

Gupta, H. V., H. Kling, K. K. Yilmaz, and F. G. Martinez, 2009: Decomposition of the mean square error and NSE performance criteria: Implications for improving hydrological modelling. J. Hydrol., 377, 80-91, doi:10.1016/j.jhydrol.2009.08.003.

Hagemann, S., and L. D. Gates, 2001: Validation of the hydrological cycle of ECMWF and NCEP reanalyses using the MPI hydrological discharge model. J. Geophys. Res., 106, 15031510, doi:10.1029/2000JD900568.

Hamlet, A. F., and D. P. Lettenmaier, 2005: Production of temporally consistent gridded precipitation and temperature fields for the continental United States. J. Hydrometeor., 6, 330-336, doi:10.1175/JHM420.1.

Hart, F. C., 1937: Precipitation and run-off in relation to altitude in the Rocky Mountain region. J. For., 35, 1005-1010.

Hayami, S., 1951: On the propagation of flood waves. Bulletin of the Disaster Prevention Research Institute, No. 1, Kyoto University, Kyoto, Japan, 1-16.

Henry, A. J., 1919: Increase of precipitation with altitude. Mon. Wea. Rev., 47, 33-41, doi:10.1175/1520-0493(1919)47<33: IOPWA $>2.0 . \mathrm{CO} ; 2$.
Hijmans, R. J., S. E. Cameron, J. L. Parra, P. G. Jones, and A. Jarvis, 2005: Very high resolution interpolated climate surfaces for global land areas. Int. J. Climatol., 25, 1965-1978, doi:10.1002/joc.1276.

Immerzeel, W. W., F. Pellicciotti, and A. B. Shrestha, 2012: Glaciers as a proxy to quantify the spatial distribution of precipitation in the Hunza basin. Mt. Res. Dev., 32, 30-38, doi:10.1659/MRD-JOURNAL-D-11-00097.1.

Jabot, E., I. Zin, T. Lebel, A. Gautheron, and C. Obled, 2012: Spatial interpolation of sub-daily air temperatures for snow and hydrologic applications in mesoscale Alpine catchments. Hydrol. Processes, 26, 2618-2630, doi:10.1002/hyp.9423.

Johansson, B., and D. Chen, 2005: Estimation of areal precipitation for runoff modelling using wind data: A case study in Sweden. Climate Res., 29, 53-61, doi:10.3354/cr029053.

Kirchner, J. W., 2009: Catchments as simple dynamical systems: Catchment characterization, rainfall-runoff modeling, and doing hydrology backward. Water Resour. Res., 45, doi:10.1029/ 2008WR006912.

Klemeš, V., 1986: Operational testing of hydrological simulation models. Hydrol. Sci. J., 31, 13-24, doi:10.1080/ 02626668609491024.

Le Moine, N., 2009: Description d'un algorithme génétique multiobjectif pour la calibration d'un modèle pluie-débit (in French). Post-Doctoral Status Rep. 2, UPMC/EDF, 13 pp. [Available online at http://www.sisyphe.upmc.fr/ lemoine/ docs/CaRaMEL.pdf.]

— , F. Hendrickx, and J. Gailhard, 2013: Rainfall-runoff modelling as a tool for constraining the reanalysis of daily precipitation and temperature fields in mountainous regions. IAHS Publ., 360, 13-18.

Legates, D. R., and C. J. Willmott, 1990a: Mean seasonal and spatial variability in global surface air temperature. Theor. Appl. Climatol., 41, 11-21, doi:10.1007/BF00866198.

— , and — 1990b: Mean seasonal and spatial variability in gauge-corrected, global precipitation. Int. J. Climatol., 10, 111-127, doi:10.1002/joc.3370100202.

Lundquist, J. D., and D. R. Cayan, 2007: Surface temperature patterns in complex terrain: Daily variations and long-term change in the central Sierra Nevada, California. J. Geophys. Res., 112, D11124, doi:10.1029/2006JD007561.

Magand, C., A. Ducharne, N. Le Moine, and S. Gascoin, 2014: Introducing hysteresis in snow depletion curves to improve the water budget of a land surface model in an Alpine catchment. J. Hydrometeor., 15, 631-649, doi:10.1175/JHM-D-13-091.1.

Matheron, G., 1974: Effet proportionnel et lognormalité ou: Le retour du serpent de mer. Note Géostatistique 124, $43 \mathrm{pp}$.

New, M., M. Hulme, and P. D. Jones, 2000: Representing twentieth century space-time climate variability. Part II: Development of 1901-96 monthly grids of terrestrial surface climate. J. Climate, 13, 2217-2238, doi:10.1175/1520-0442(2000)013<2217: RTCSTC $>2.0 . \mathrm{CO} ; 2$.

, D. Lister, M. Hulme, and I. Makin, 2002: A high-resolution data set of surface climate over global land areas. Climate Res., 21, 1-15, doi: $10.3354 / \mathrm{cr} 021001$.

Oudin, L., F. Hervieu, C. Michel, C. Perrin, V. Andréassian, F. Anctil, and C. Loumagne, 2005: Which potential evapotranspiration input for a lumped rainfall-runoff model?: Part 2-Towards a simple and efficient potential evapotranspiration model for rainfall-runoff modelling. J. Hydrol., 303, 290306, doi:10.1016/j.jhydrol.2004.08.026.

Paquet, E., J. Gailhard, and R. Garçon, 2006: Évolution de la méthode du gradex: Approche par type de temps et 
modélisation hydrologique. Houille Blanche, 5, 80-90, doi:10.1051/lhb:2006091.

Press, W. H., S. Teukolsky, W. Vetterling, and B. Flannery, 1992: Numerical Recipes in C. 2nd ed. Cambridge University Press, 994 pp.

Roe, G. H., 2005: Orographic precipitation. Annu. Rev. Earth Planet. Sci., 33, 645-671, doi:10.1146/annurev.earth.33.092203.122541.

Rothfuss, Y., I. Braud, N. Le Moine, P. Biron, J.-L. Durand, M. Vauclin, and T. Bariac, 2012: Factors controlling the isotopic partitioning between soil evaporation and plant transpiration: Assessment using a multi-objective calibration of SiSPAT-Isotope under controlled conditions. J. Hydrol., 442443, 75-88, doi:10.1016/j.jhydrol.2012.03.041.

Siler, N., and G. Roe, 2014: How will orographic precipitation respond to surface warming? An idealized thermodynamic perspective. Geophys. Res. Lett., 41, 2606-2613, doi:10.1002/ 2013 GL059095.

Skøien, J. O., R. Merz, and G. Blöschl, 2006: Top-krigingGeostatistics on stream networks. Hydrol. Earth Syst. Sci., 10, 277-287, doi:10.5194/hess-10-277-2006.

Thornton, P. E., S. W. Running, and M. A. White, 1997: Generating surfaces of daily meteorology variables over large regions of complex terrain. J. Hydrol., 190, 214-251, doi:10.1016/ S0022-1694(96)03128-9.
Valéry, A., V. Andréassian, and C. Perrin, 2009: Inverting the hydrological cycle: When streamflow measurements help assess altitudinal precipitation gradients in mountain areas. IAHS Publ., 333, 281-286.

Vischel, T., T. Lebel, S. Massuel, and B. Cappelaere, 2009: Conditional simulation schemes of rain fields and their application to rainfall-runoff modeling studies in the Sahel. J. Hydrol., 375, 273-286, doi:10.1016/j.jhydrol.2009.02.028.

Viviroli, D., and R. Weingartner, 2008: "Water towers"-A global view of the hydrological importance of mountains. Mountains: Sources of Water, Sources of Knowledge, E. Wiegandt, Ed., Advances in Global Change Research, Vol. 31, Springer, 1520, doi:10.1007/978-1-4020-6748-8_2.

Weingartner, R., D. Viviroli, and B. Schädler, 2007: Water resources in mountain regions: A methodological approach to assess the water balance in a highland-lowland-system. $\mathrm{Hy}$ drol. Processes, 21, 578-585, doi:10.1002/hyp.6268.

Willmott, C. J., and S. M. Robeson, 1995: Climatologically aided interpolation (CAI) of terrestrial air temperature. Int. J. Climatol., 15, 221-229, doi:10.1002/joc.3370150207.

Yan, Z., L. Gottschalk, E. Leblois, and J. Xia, 2012: Joint mapping of water balance components in a large Chinese basin. J. Hydrol., 450-451, 59-69, doi:10.1016/j.jhydrol.2012.05.030. 